\title{
TU/e EmonONEN

\section{Ab Initio calculations of intermediates of oxygen reduction on low-index platinum surfaces}

\section{Citation for published version (APA):}

Panchenko, A., Koper, M. T. M., Shubina, T. E., Mitchell, S. J., \& Roduner, E. (2004). Ab Initio calculations of intermediates of oxygen reduction on low-index platinum surfaces. Journal of the Electrochemical Society, 151(12), A2016-A2027. https://doi.org/10.1149/1.1809586

DOI:

10.1149/1.1809586

Document status and date:

Published: 01/01/2004

\section{Document Version:}

Publisher's PDF, also known as Version of Record (includes final page, issue and volume numbers)

\section{Please check the document version of this publication:}

- A submitted manuscript is the version of the article upon submission and before peer-review. There can be important differences between the submitted version and the official published version of record. People interested in the research are advised to contact the author for the final version of the publication, or visit the $\mathrm{DOI}$ to the publisher's website.

- The final author version and the galley proof are versions of the publication after peer review.

- The final published version features the final layout of the paper including the volume, issue and page numbers.

Link to publication

\section{General rights}

Copyright and moral rights for the publications made accessible in the public portal are retained by the authors and/or other copyright owners and it is a condition of accessing publications that users recognise and abide by the legal requirements associated with these rights.

- Users may download and print one copy of any publication from the public portal for the purpose of private study or research.

- You may not further distribute the material or use it for any profit-making activity or commercial gain

- You may freely distribute the URL identifying the publication in the public portal.

If the publication is distributed under the terms of Article 25fa of the Dutch Copyright Act, indicated by the "Taverne" license above, please follow below link for the End User Agreement:

www.tue.nl/taverne

Take down policy

If you believe that this document breaches copyright please contact us at:

openaccess@tue.nl

providing details and we will investigate your claim. 


\title{
$A b$ Initio Calculations of Intermediates of Oxygen Reduction on Low-Index Platinum Surfaces
}

\author{
A. Panchenko, ${ }^{a}$ M. T. M. Koper, ${ }^{\text {b }}$ T. E. Shubina, ${ }^{\text {b }}$ S. J. Mitchell, ${ }^{\text {b }}$ \\ and E. Roduner ${ }^{\mathrm{a}, \mathrm{z}}$ \\ ${ }^{a}$ Institut für Physikalische Chemie, Universität Stuttgart, D-70569 Stuttgart, Germany \\ ${ }^{b}$ Schuit Institute of Catalysis, Laboratory of Inorganic Chemistry and Catalysis, Eindhoven University \\ of Technology, 5600 MB Eindhoven, The Netherlands
}

\begin{abstract}
Properties of the oxygen molecule, atomic oxygen, and intermediate products of its reduction, $\mathrm{OH}, \mathrm{OOH}, \mathrm{H}_{2} \mathrm{O}_{2} \mathrm{On}(111),(100)$, and (110) Pt surfaces have been investigated using periodic density functional theory. The Pt surfaces are modeled as four-layer slabs. Adsorption energies and geometries, as well as the charge-transfer properties are calculated. Computed characteristics of the adsorbed oxygen reduction intermediates supply known tendencies of the low index Pt surface activities under different experimental conditions. Electric field dependencies of the properties of all species adsorbed on a $\mathrm{Pt}_{9}(111)$ cluster have been also studied. Lowering the field causes an increase of the $\mathrm{O}-\mathrm{O}$ bond length of $\mathrm{O}_{2 \text { ads }}$, attracting the molecule to the Pt surface and increasing the charge transfer from Pt to $2 \pi^{*}$ orbitals of the oxygen molecule. The weakening of the O-O bond is evidenced by a decrease of the $\mathrm{O}-\mathrm{O}$ stretching frequency. The charge-transfer from the $\mathrm{Pt}_{9}$ cluster to the adsorbates is observed for all species In our calculations hydrogen peroxide was unstable on all three low-index Pt surfaces and dissociated into two hydroxyls or a water molecule and atomic oxygen. The results of the calculations are discussed in the context of the mechanism of oxygen reduction.
\end{abstract}

(C) 2004 The Electrochemical Society. [DOI: 10.1149/1.1809586] All rights reserved.

Manuscript submitted February 4, 2004; revised manuscript received April 21, 2004. Available electronically October $28,2004$.

Platinum catalysts are involved in a vast variety of redox reactions, and $\mathrm{O}_{2}$ reduction is one of the most important of them. Therefore, considerable efforts are undertaken by electrochemists to understand the fundamental aspects of Pt catalysts and to improve the properties of applied catalytic systems in general. The fundamental relevance of Pt catalytic properties has become even more important because carbon-supported $\mathrm{Pt}$ catalysts have so far been the best choice for the oxygen reduction at the cathode of low-temperature polymer electrolyte membrane fuel cells (PEMFCs). ${ }^{1}$

The oxygen reduction reaction (ORR) on Pt surfaces has been widely studied in electrochemistry, but the details of the mechanism remain elusive. The overall ORR is a multistep process involving four electron transfers during which bonds are broken and formed. It is still not clear whether the process starts from the oxygen molecule dissociation on Pt electrodes, this being followed by electron and proton transfer, or whether the first reduction step happens before $\mathrm{O}-\mathrm{O}$ bond cleavage. Damjanovic proposed that the first step is an electron transfer to the $\mathrm{O}_{2}$ molecule

$$
\mathrm{O}_{2}+\mathrm{e}^{-} \rightarrow \mathrm{O}_{2}^{-}
$$

This step is rate-determining and is either accompanied by or followed by a fast proton transfer. ${ }^{2,3}$ In solution, this step is endorgonic by $-0.33 \mathrm{~V}^{4}$ Recent results by Markovic et al. ${ }^{5}$ support this proposal based on their experiments on oxygen reduction at singlecrystal electrodes.

A theoretical study by Sidik et al. has proven the first electron transfer to be rate-determining on dual adsorption sites. Proton transfer is involved in this step, because the electron affinity of the reactant complex is increased significantly by the proton field, and this lowers the activation energy for reduction. ${ }^{6}$ In the potential range of $0.47-1.20 \mathrm{~V}$, the calculated barrier for the formation of $\mathrm{OOH}$ is lower than the calculated $0.74 \mathrm{eV} \mathrm{O}_{2}$ dissociation barrier, implying that $\mathrm{O}_{2}$ does not dissociate on the Pt electrode before the first electron transfer.

From the experimental point of view, there is evidence for the dissociative adsorption of $\mathrm{O}_{2}$ at the platinum-ultrahigh vacuum (UHV) interface at room temperature, ${ }^{7}$ but there is no evidence for the direct cleavage of the $\mathrm{O}-\mathrm{O}$ bond at the electrochemical interfaces.

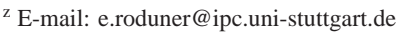

In general, $\mathrm{O}_{2}$ reduces by either $2 \mathrm{e}^{-}$to $\mathrm{H}_{2} \mathrm{O}_{2}$, or by $4 \mathrm{e}^{-}$to $\mathrm{H}_{2} \mathrm{O}$, depending on the electrode material and surface modifications. ${ }^{3}$ Adzic and co-workers ${ }^{8}$ distinguish the following pathways: (i) a direct four-electron reduction to $\mathrm{H}_{2} \mathrm{O}$ (in acidic media) or to $\mathrm{OH}^{-}$(in alkaline media) without hydrogen peroxide detected on the ring electrode; (ii) a two-electron pathway involving reduction to hydrogen peroxide; (iii) a series of pathways with two- and fourelectron reduction; (iv) a parallel pathway that is a combination of $(i),(i i)$, and $(i i i) ;(v)$ an interactive pathway in which diffusion of species from the series pathway into a direct pathway is possible.

It is now well-established that the reaction rates of the oxygen reduction on different low-index Pt surfaces are structure sensitive, due to structure-sensitive adsorption of spectator species, such as $\mathrm{O}_{2 \text { ads }}, \mathrm{OH}_{\mathrm{ads}}$, and $\mathrm{OOH}_{\mathrm{ads}}$. The adsorption properties of the $\mathrm{OH}$ species are probably the most important in the process. In $0.05 \mathrm{M}$ $\mathrm{H}_{2} \mathrm{SO}_{4}$ the ORR rate increases in the sequence $\mathrm{Pt}(111)<\mathrm{Pt}(100)$ $<\operatorname{Pt}(110) .{ }^{9}$ An exceptionally large deactivation is observed at the (111) surface probably due to competition of the strongly adsorbing (bi)sulfate anion. In perchloric acid solution, the variation in activity at $0.8-0.9 \mathrm{~V}$ is relatively small between the three low index faces, with the activity increasing in the order $(100)<(110) \approx(111) .{ }^{5} \mathrm{~A}$ similar structural sensitivity is observed in $0.1 \mathrm{M} \mathrm{KOH}$. In the potential range where $\mathrm{O}_{2}$ reduction is under combined kineticdiffusion control $(E>0.75 \mathrm{~V})$, the activity increases in the sequence $(100)<(110)<(111) .{ }^{10}$ The decrease of the $(100)$ surface activity is related to a high affinity of (100) sites for the hydroxyl adsorption, leading to a lack of active centers for $\mathrm{O}_{2}$ adsorption on $\mathrm{Pt}(100)$ as it is highly covered with $\mathrm{OH}_{\text {ads }}$. Markovic et al. suggested that the rate of $\mathrm{O}_{2}$ reduction should be proportional to that part of the surface not covered by the hydroxyl species $\left(1-\Theta_{\mathrm{OH}}\right)$. As is shown below, our computational results also support a structural sensitivity of the oxygen molecule and the oxygen reduction intermediates, in particular through the strong adsorption of $\mathrm{OH}$ on $\mathrm{Pt}(100)$.

Theoretical studies of oxygen-containing species adsorbed on the Pt surface yield detailed information about the adsorption and reaction properties on a molecular level. Because of the importance of the system, the adsorption of (molecular) oxygen species has been a key issue of theoretical investigations by a large number of specialists, but in most cases the studies were restricted to the (111) and (100) surfaces. ${ }^{11-13}$

Using a single platinum atom for coordinating $\mathrm{O}_{2}, \mathrm{H}_{2} \mathrm{O},{ }^{\circ} \mathrm{OOH}$, 
$\mathrm{H}_{2} \mathrm{O}_{2}$, and ${ }^{\circ} \mathrm{OH}$ intermediates in the oxygen reduction, Anderson and co-workers suggested the following lowest energy singleelectron pathway for oxygen reduction ${ }^{11}$

$$
\begin{gathered}
\mathrm{Pt}+\mathrm{O}_{2} \rightarrow \text { Pt-O } \\
\text { Pt-O }{ }_{2}+\mathrm{H}^{+}(\text {aq })+\mathrm{e}^{-}(\mathrm{U}) \rightarrow \mathrm{Pt}-\mathrm{OOH} \\
\mathrm{Pt}-\mathrm{OOH}+\mathrm{H}^{+}(\mathrm{aq})+\mathrm{e}^{-}(\mathrm{U}) \rightarrow \mathrm{Pt}-\mathrm{O}+\mathrm{H}_{2} \mathrm{O} \\
\mathrm{Pt}-\mathrm{O}+\mathrm{H}^{+}(\mathrm{aq})+\mathrm{e}^{-}(\mathrm{U}) \rightarrow \mathrm{Pt}-\mathrm{OH} \\
\mathrm{Pt}-\mathrm{OOH}+\mathrm{H}^{+}(\mathrm{aq})+\mathrm{e}^{-}(\mathrm{U}) \rightarrow \mathrm{Pt}-(\mathrm{OHOH}) \\
\mathrm{Pt}-(\mathrm{OHOH})+\mathrm{H}^{+}(\mathrm{aq})+\mathrm{e}^{-}(\mathrm{U}) \rightarrow \mathrm{Pt}-\mathrm{OH}+\mathrm{H}_{2} \mathrm{O} \\
\mathrm{Pt}-\mathrm{OH}+\mathrm{H}^{+}(\mathrm{aq})+\mathrm{e}^{-}(\mathrm{U}) \rightarrow \mathrm{Pt}-\mathrm{OH}_{2}
\end{gathered}
$$

Compared to the uncatalyzed outer Helmholtz plane values, bonding to the platinum atom has the effect of decreasing the calculated activation energies for $\mathrm{O}_{2}$ and $\mathrm{H}_{2} \mathrm{O}_{2}$ reduction. The activation energies for $\mathrm{OH}$ radical reduction to $\mathrm{H}_{2} \mathrm{O}$ increase when ${ }^{\circ} \mathrm{OH}$ is bonded to the $\mathrm{Pt}$ atom, and bonding to $\mathrm{Pt}$ decreases the activation energies of ${ }^{\circ} \mathrm{OOH}$ reduction to $\mathrm{H}_{2} \mathrm{O}_{2}$. The activation energies are predicted to increase with increasing potential. Anderson's calculations predict an activation energy of $0.43 \mathrm{eV}$ for oxygen reduction at the standard equilbrium potential. At $1.23 \mathrm{~V}$ the experimental activation energy is $0.44 \mathrm{eV}$ on the three low-index Pt surfaces in 0.05 $\mathrm{M} \mathrm{H}_{2} \mathrm{SO}_{4} \cdot{ }^{14}$ The rate-determining step appears to be the addition of the first electron to $\mathrm{O}_{2 \text { ads }} \cdot{ }^{3}$ Hartnig and Koper have recently modeled this electron addition as a Marcus-type outer-sphere electron transfer reaction using large-scale molecular dynamics simulations. $^{15}$

A reaction that interferes with the redox system is the oxidation of the water molecule

$$
\mathrm{Pt}-\mathrm{OH}_{2} \rightarrow \mathrm{Pt}-\mathrm{OH}+\mathrm{H}^{+}+\mathrm{e}^{-}
$$

which leads to adsorbed hydroxyl radicals. ${ }^{16}$ Reaction 9 is the main source of adsorbed $\mathrm{OH}$ in the system and therefore primarily responsible for the surface poisoning, i.e., the $\left(1-\Theta_{\mathrm{OH}}\right)$ term mentioned above.

In the present work we want to calculate the system properties by performing calculations at a high level of theory for (111), (100), and (110) surfaces for (radical) intermediates of the oxygen reduction.

Radicals are deemed important for understanding the degradation effects in a working fuel cell. ${ }^{17}$ It is therefore of key interest to explore the energetics of reaction intermediates on Pt surfaces. How strongly do the radicals adsorb and under what conditions do they leave the surface of the Pt catalyst to deploy their destructive nature? Under different fuel cell running conditions the catalyst experiences different electric potentials. Which influences can it have on the adsorption/desorption of the oxygen species and on the catalytic reaction in general? The present work tries to provide insight into these issues.

The main results of our computations are the potential-dependent adsorption properties of oxygen and intermediates of the reduction of oxygen on the three low-index platinum surfaces (111), (110), and (100). It is now generally accepted that the slab geometry with periodic boundary conditions is the best model for obtaining accurate chemisorption energies and geometries on the surface. Therefore, such calculations have been used for the present purpose. Cluster models can describe local properties such as adsorbate geometries, vibrational frequencies, and bonding mechanism. ${ }^{18}$ Moreover, it was shown recently that for $\mathrm{CO}$ and $\mathrm{OH}^{-}$adsorbed on $\mathrm{Pt}$, the cluster model can be successfully applied for the description of the Stark tuning rate. ${ }^{19,20}$ Therefore, we have used a cluster model to describe properties of the adsorbed oxygen-containing species as a function of an applied electric field, as this also leads to a significant reduction of computation time.

\section{Background}

In this section, we briefly (and incompletely) discuss some results from fundamental experimental and computational studies concerning the species of interest in our computations. Most of these studies were carried out for the platinum-UHV interface, which leads to the best-defined conditions. We point out that these are not necessarily the conditions most applicable to the electrochemical interface.

Oxygen adsorption.-The adsorption of oxygen on Pt surfaces has been identified as a fundamental step of its reduction mechanism. ${ }^{21,22}$ Experiments at the platinum-UHV interface have shown that oxygen adsorbs both dissociatively and molecularly on the (111) surface. Adsorbed molecular oxygen is found at $150 \mathrm{~K}$; at higher temperatures dissociation takes place. ${ }^{7}$

Previous spectroscopic studies identified three distinct chemisorbed states of oxygen on the $\mathrm{Pt}(111)$ surface. Two of them are adsorbed molecular species, the superoxo-like $\left(\mathrm{O}_{2}^{-}\right)$state is formed at bridge sites with an intramolecular bond order of 1.5 and a vibrational frequency of $870 \mathrm{~cm}^{-1}$, and the peroxo-like $\left(\mathrm{O}_{2}^{2-}\right)$ state formed at threefold hollow sites with an intramolecular bond order of 1.0 and a stretching frequency of $690 \mathrm{~cm}^{-1} \cdot 13,23$ At near-zero surface coverages the peroxo-like molecular precursor is observed exclusively, while both the superoxo-like and peroxo-like forms are detected at higher coverages. ${ }^{24,25}$

Because of an additional electron in the antibonding $\pi$ orbital of the molecule the peroxo-like oxygen is often referred to as a precursor state for dissociation. ${ }^{26}$ Dissociation on $\mathrm{Pt}(111)$ proceeds by sequential population of superoxo-like and peroxo-like precursor states. ${ }^{21}$ Atomic oxygen is by far the energetically most stable configuration of oxygen on Pt surfaces. Upon heating to above 150 $\mathrm{K}$, both molecular species disappear in favor of atomic oxygen that is observed in threefold hollow sites, featuring a Pt-O bond frequency of $471 \mathrm{~cm}^{-1} .^{27}$

$\mathrm{OH}$ adsorption.-Hydroxyl adsorbates are key intermediates on the PEMFC cathode as they are generally held responsible for blocking adsorption sites for oxygen. Spectroscopic investigations of hydroxyl groups on low-index Pt surfaces have been the focus of recent research in many groups. On $\mathrm{Pt}(111)$, Fisher and Sexton reported that $\mathrm{OH}_{\text {ads }}$ could be prepared by adsorption of $\mathrm{H}_{2} \mathrm{O}$ on a layer of preadsorbed $\mathrm{O}$ atoms at $100 \mathrm{~K}$ and subsequent heating above $T=150 \mathrm{~K}$, leading to the formation of $\mathrm{OH}$ groups. ${ }^{28} \mathrm{It}$ is a matter of debate and possibly depends on the method of preparation ${ }^{29}$ whether $\mathrm{OH}_{\text {ads }}$ is bound at top positions or in threefold hollow sites. $^{30}$

Previous theoretical studies of the system have shown that at low coverages (from $1 / 9$ of a monolayer (ML) to $1 / 3$ of a ML) OH binds preferentially at bridge and top sites with a chemisorption energy of $\sim 2.25 \mathrm{eV}^{31}$ At high coverages (1/2 to $\left.1 \mathrm{ML}\right) \mathrm{H}$ bonding between adjacent hydroxyl groups leads to $(i)$ an enhancement in $\mathrm{OH}$ chemisorption energy by about 15\%; (ii) a strong preference for $\mathrm{OH}$ adsorption at top sites; and (iii) the formation of $\mathrm{OH}$ networks.

Koper and co-workers found that $\mathrm{OH}$ has a tendency to adsorb upright in the hollow site. ${ }^{32}$ However, both in the atop and bridge positions, a tilting of the molecule leads to significant lowering of the binding energy on platinum. More importantly, when coadsorbed with water on $\mathrm{Rh}(111)$, a discrete Fourier transform (DFT) study by Vassilev et al. showed that $\mathrm{OH}$ lies almost flat on the surface, with the oxygen coordinated to a top surface atom. ${ }^{33}$

$\mathrm{H}_{2} \mathrm{O}_{2}$ adsorption.-Depending on the properties of the Pt electrode surface $\mathrm{H}_{2} \mathrm{O}_{2}$ can be formed in appreciable amounts during the ORR. The yield of hydrogen peroxide on a typical fuel cell catalyst such as Pt/Vulcan amounts to $c a$. $15 \%$, in a close agreement with the average value of $\mathrm{H}_{2} \mathrm{O}_{2}$ produced on $\mathrm{Pt}(100)(c a .25 \%)$ and $\mathrm{Pt}(110)$ (ca. $2.5 \%$ ) single-crystal surfaces. ${ }^{8}$

Hydrogen peroxide is unstable on low-index Pt surfaces and decays into a water molecule and molecular oxygen ${ }^{34}$ 


$$
2 \mathrm{H}_{2} \mathrm{O}_{2} \rightarrow 2 \mathrm{H}_{2} \mathrm{O}+\mathrm{O}_{2}
$$

The activation energy for the Pt-catalyzed reaction amounts to about $54.4 \mathrm{~kJ} \mathrm{~mol}^{-1}$. Furthermore, $\mathrm{H}_{2} \mathrm{O}_{2}$ can dissociate on Pt surfaces into two hydroxyls. Another path that has been suggested includes the formation of $\mathrm{OOH}$ radicals and $\mathrm{H}$ atoms $\mathrm{s}^{35,36}$

$$
\begin{aligned}
& \text { Pt- } \mathrm{H}_{2} \mathrm{O}_{2}+\rightarrow \mathrm{Pt}-\mathrm{OH}+\mathrm{Pt}-\mathrm{OH} \\
& 2 \mathrm{Pt}+\mathrm{H}_{2} \mathrm{O}_{2} \rightarrow \mathrm{Pt}-\mathrm{OOH}+\mathrm{Pt}-\mathrm{H}
\end{aligned}
$$

It has been proposed that $\mathrm{OH}_{\text {ads }}$ initiates the autocatalytic dissociative adsorption of hydrogen peroxide.

$\mathrm{H}_{2} \mathrm{O}$ adsorption.-When one speaks about the ORR on metal surfaces one has to take into account that the surface is not clean but always covered with adsorbed water molecules. Intermediates of the oxygen reduction are thus solvated on the surface. The water-metal interaction has been one of the most studied adsorption cases since the establishment of modern surface science some 25 years ago. ${ }^{37}$

Ogasawara et al. found that water on the $\mathrm{Pt}(111)$ surface forms a nearly flat overlayer with both metal-oxygen and metalhydrogen bonds formed to the surface. ${ }^{38}$ A recent DFT study showed that, whereas a single water molecule adsorbs flat on $\mathrm{Pt}(111)$ with a binding energy of $c a$. $0.3 \mathrm{eV}$, the binding energy in a bilayer (twothirds coverage) increases to $c a$. $0.53 \mathrm{eV}$ due to hydrogen bond formation. 39

\section{Computational Methods}

First-principles total energy calculations within the DFT framework were performed in this study. As mentioned in the introduction, two geometrical models were used to study adsorption, the slab geometry and the cluster geometry. The former was studied using the VASP program; the latter using Gaussian 98.

VASP slab calculations.-The calculations were carried out with the Vienna Ab-Initio Simulation Package, VASP, ${ }^{40}$ which is an efficient density-functional-theory-based code for systems with periodic boundary conditions.

The VASP represents the electron-ion core interaction via Blöchl's projector augmented wave (PAW) approach. ${ }^{41}$ Generally the PAW potentials are more accurate than the ultrasoft (US) pseudopotentials because the radial cutoffs (core radii) are smaller than the radii used for the US pseudopotentials, and because the PAW potentials reconstruct the exact valence wave function with all nodes in the core region. The PAW method yields converged total energy differences with a modest plane-wave basis set. The Vosko-Wilk-Nusair $^{42}$ form of the local density approximation was used, in combination with the PW91 functional for the generalized gradient approximation (GGA) ${ }^{43}$ In all cases, the plane-wave expansion was truncated at a cutoff energy of $400 \mathrm{eV}$, and a grid of $5 \times 5 \times 1$ Monkhorst-Pack special k-points was used to perform the Brillouin-zone integrations. These settings were found to give binding energies which converged to within $0.02 \mathrm{eV}$ with a minimum of computational cost. Adsorption energies were calculated as the difference between the energy of the composite system and the sum of the energies of the clean surface and uncoordinated adsorbate. For example, the chemisorption energy of atomic oxygen was calculated from

$$
E_{\mathrm{ads}}=E_{\mathrm{Pt}-\mathrm{O}}-\left(E_{\mathrm{O}}+E_{\mathrm{Pt}}\right)
$$

where $E_{\mathrm{O}}, E_{\mathrm{Pt}}$, and $E_{\mathrm{Pt} / \mathrm{O}}$ are the total energies of free $\mathrm{O}, \mathrm{Pt}$, and Pt-O.

The surfaces were modeled as four-layer slabs having four atoms in each layer, separated by five layers of vacuum. All calculations were performed at the equilibrium lattice constant of $2.82 \AA$ as found from the VASP geometry optimization. Pt atoms in the first layer were allowed to relax in the direction perpendicular to the surface.

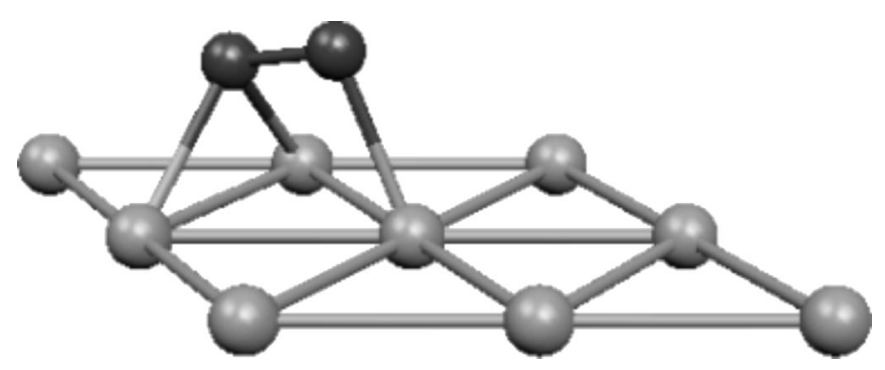

Figure 1. Oxygen molecule adsorbed at the hollow position of $\mathrm{at}_{9}(111)$ cluster.

Gaussian 98 cluster calculations. - In this part of the study we used a cluster model to simulate the interactions of oxygencontaining species with different sites of the $\mathrm{Pt}(111)$ surface in the presence of an applied electric field. Optimized geometries of adsorbed species were taken from the VASP results and reoptimized for the case of the $\mathrm{Pt}_{9}(111)$-adsorbate system. The cluster geometry was fixed as in bulk platinum, with an experimental Pt-Pt distance of $2.77 \AA$. Figure 1 shows the geometry of an adsorbed oxygen molecule at the hollow position on the $\mathrm{Pt}_{9}(111)$ cluster. The small size of the cluster provides only a limited representation of the metal conduction band. Therefore, one does not expect to obtain extremely accurate results. However, common trends, in particular in relation to bond distances and vibration properties, and the effect of an electric field on the binding energy should be sufficiently accurate to produce meaningful results. ${ }^{18,44}$

We employed a $6-311 \mathrm{G}^{* *}$ basis set for the $\mathrm{O}$ and $\mathrm{H}$ atoms and a LANL2DZ, double-s, basis with an effective core potential derived by Hay and Wadt ${ }^{45}$ for the Pt atoms as implemented in Gaussian $98 .{ }^{46}$ Using these basis sets and frozen core potentials, $a b$ initio cluster model calculations were carried out in the framework of the B3LYP density functional theory method with spinunrestricted orbitals. The B3LYP hybrid method is known to provide very good results for transition-metal-containing compounds including surface cluster models. ${ }^{47,48}$ The B3LYP functional is based on Becke's three-parameter adiabatic connection method (ACM) approach, and consists of a combination of Slater, ${ }^{49}$ Hartree-Fock, ${ }^{50}$ and Becke ${ }^{51}$ exchange, with the Vosko, Wilk, and Nusair (VWN) local $^{42}$ and the Lee, Yang, and Parr (LYP) $)^{52,53}$ nonlocal correlation functionals.

In order to investigate the electric field dependence of the properties of the adsorbed species, an electric field was applied to the system in a direction perpendicular to the Pt surface. Electric field intensities of $-0.0100,-0.0075,-0.0050,-0.0025,0.0000$ $0.0025,0.0050,0.0075,0.0100$ a.u. were considered, and the sign of the electric field was chosen in such a way that a more negative field corresponds to a more negative adsorbate and more positive Pt substrate. The electric potential is the relevant experimental parameter, which determines the electrochemical properties of adsorbates, as reflected in particular in their vibrational characteristics. ${ }^{19,54,55}$ Some of these vibrational characteristics may be measured experimentally by surface-enhanced Raman spectroscopy (SERS), sum frequency generation (SFG), and infrared reflectance-absorption spectroscopy (IRAS) ${ }^{56-58}$ Geometries of the adsorbates were optimized for each field using analytical gradients.

In general, the theoretical DFT studies give bond distances and vibrational frequencies close to the experimental values, both for slab and cluster models of the surface. ${ }^{13,32}$ However, clusters of $\approx 28$ atoms or more might be required for an accurate description of binding energies. ${ }^{12}$ The adsorption energy is generally more sensitive to the size and shape of the cluster than the distances are, as the energy levels of the cluster orbitals play an important role in the bonding. However, in some cases, clusters as small as $\mathrm{Pt}_{2}$ or even single $\mathrm{Pt}$ atoms provide reasonable estimates of metal-adsorbate bond strengths on extended Pt surfaces. ${ }^{6}$ 
Table I. Bond lengths and stretching frequencies of the $\mathrm{O}_{2}, \cdot \mathrm{O}-\mathrm{OH}$, and $\mathrm{H}_{2} \mathrm{O}_{2}$ obtained by experiment, VASP, and Gaussian 98.

\begin{tabular}{|c|c|c|c|c|c|c|}
\hline & \multicolumn{2}{|c|}{$\mathrm{O}-\mathrm{O}$} & \multicolumn{2}{|c|}{$\cdot \mathrm{O}-\mathrm{OH}$} & \multicolumn{2}{|c|}{$\mathrm{HO}-\mathrm{OH}$} \\
\hline & $\begin{array}{c}\text { Bond } \\
\text { length }(\AA)\end{array}$ & $\begin{array}{l}\text { Frequency } \\
\left(\mathrm{cm}^{-1}\right)\end{array}$ & $\begin{array}{c}\text { Bond } \\
\text { length }(\AA)\end{array}$ & $\begin{array}{l}\text { Frequency } \\
\left(\mathrm{cm}^{-1}\right)\end{array}$ & $\begin{array}{c}\text { Bond } \\
\text { length }(\AA)\end{array}$ & $\begin{array}{l}\text { Frequency } \\
\left(\mathrm{cm}^{-1}\right)\end{array}$ \\
\hline $\begin{array}{l}\text { VASP } \\
\text { (PW91-GGA/PAW) }\end{array}$ & 1.24 & 1516 & 1.35 & 1174 & 1.48 & 994 \\
\hline $\begin{array}{l}\text { Gaussian } 98 \\
(\text { B3LYP/6-311G**) }\end{array}$ & 1.21 & 1578 & 1.33 & 1163 & 1.45 & 943 \\
\hline $\begin{array}{l}\text { Experiment } \\
\text { (Ref. 74-78) }\end{array}$ & 1.208 & 1580 & $\begin{array}{c}1.372 \\
\text { (Ref. 79) }\end{array}$ & 1098 & 1.490 & 890 \\
\hline
\end{tabular}

\section{Results and Discussion}

Uncoordinated species.-Table I summarizes bond lengths and stretching frequencies of the oxygen and products of consecutive one-electron additions to the $\mathrm{O}_{2}$ molecule in the gas phase. The computational approaches applied in this study are known to yield reasonable results for the oxygen containing species on $\mathrm{Pt}$ clusters $^{12,20}$ and extended surfaces. ${ }^{13,32}$ In our surface calculations we neutralize the oxygen reduction intermediates with protons to $\mathrm{OOH}, \mathrm{H}_{2} \mathrm{O}_{2}$, and $\mathrm{OH}$, and we believe that these species play the principal role for understanding the process of oxygen reduction in a running fuel cell.

Both the VASP (PW91-GGA/PAW) and Gaussian 98 (B3LYP/ 6-311G**) computations describe the oxygen molecule, superoxo radical, and hydrogen peroxide in the gas phase reasonably well, although VASP slightly overestimates the O-O bond length for $\mathrm{O}_{2}$, and Gaussian 98 underestimates the bond for the ${ }^{\circ} \mathrm{OOH}$ and $\mathrm{H}_{2} \mathrm{O}_{2}$ species that causes corresponding shifts of the vibrational frequencies.

However, it is well known that DFT methods can fail to accurately describe electron affinities and ionization potentials of weakly bound anions, in particular oxides. High-level methods, e.g., MRCI or $\operatorname{CSSD}(\mathrm{T})$ using large basis sets are necessary to obtain quantitative agreement with experiments. ${ }^{59}$ Calculations at these levels have not been carried out for the surface-adsorbate system due to the large amount of CPU time necessary.

$\mathrm{O}_{2}$ adsorption.-The adsorption of oxygen on platinum surfaces is a fundamental step in its reduction mechanism. Full optimization of adsorbed oxygen molecules was performed for several possible sites on the Pt surface, yielding adsorption energy, adsorption geometry, and charge transfer. In agreement with previous studies of the

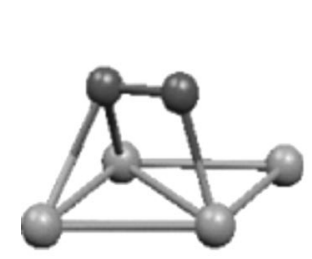

a)

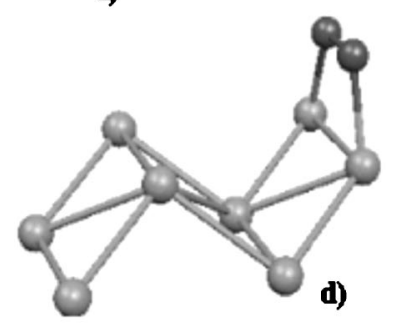

b)

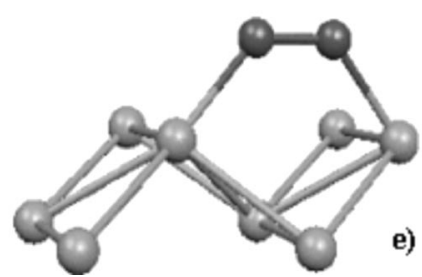

Figure 2. Oxygen molecule adsorbed on low index Pt surfaces: (a) hollow position on (111), (b) bridge position on (111), (c) bridge position on (100), (d) short bridge position on (110), (e) long bridge position on (110). system $^{13,23}$ we found three favorable positions for molecular oxygen adsorption on $\operatorname{Pt}(111)$. Two of them are almost identical and correspond to the hollow position (fcc and hcp) between three Pt atoms (Fig. 2a) with adsorption energies of -0.52 and $-0.46 \mathrm{eV}$, respectively, whereas the third so-called bridge position between two Pt atoms (Fig. 2b) is the most stable. The O-O bond length is stretched from its gas-phase value of 1.24 to 1.38 and $1.36 \AA$ for the hollow and bridge positions, respectively.

In order to evaluate the extent of consistency between the VASP calculations with periodic boundary conditions and the Gaussian 98 calculations on the isolated $\mathrm{Pt}_{9}(111)$ cluster (Fig. 1) we performed a test calculation with VASP for $\mathrm{O}_{2}$ adsorbed on the $\mathrm{Pt}_{9}(111)$ cluster as the repetitive element resulted in adsorption energies of -0.17 and $-0.32 \mathrm{eV}$ for the hollow and bridge positions, respectively. The decrease of the adsorption energy is caused by the fact that the Pt-Pt optimized distance is calculated to be $0.05 \AA$ longer, and therefore the cluster is under stress. Moreover, Pt atoms in the cluster are not allowed to relax in the presence of the adsorbed oxygen molecule. The O-O bond length on the $\mathrm{Pt}_{9}(111)$ cluster was calculated to be 1.31 and $1.30 \AA$ for the hollow and bridge positions, respectively, but the molecule moved away from the surface to $2.11 \AA$ and $2 \times 2.45 \AA$ Pt-O distances for the hollow position and $2.15 \AA$ for the bridge position. The cluster studies of the adsorption characteristics delivers the right trend in energies and geometries, but a fourlayer slab model is essential for obtaining reasonable results that compare favorably to scanning tunneling microscopy (STM) and energy electron loss spectroscopy (EELS) experiments on extended $\operatorname{Pt}(111)$ surfaces. ${ }^{24,25}$

On the (100) surface we found one site of preferential molecular adsorption. The oxygen molecule lies between two Pt atoms (Fig. 2c).

On the (110) surface we found two favorable states of oxygen adsorption, which are the different bridge positions between two neighboring Pt atoms in the first layer (Fig. $2 \mathrm{~d}$ and e). At the short bridge position the $\mathrm{O}-\mathrm{O}$ bond is stretched to $1.38 \AA$, whereas at the long bridge site the bond is computed to be slightly shorter. Some selected properties of the adsorbed $\mathrm{O}_{2}$ are given in Table II. Note that the short-bridge position on the (110) surface is the most favorable adsorption site for the oxygen molecule among the three low-

Table II. Selected properties of the $\mathrm{O}_{2}$ molecule adsorbed on low index Pt surfaces derived from the VASP (PW91-GGA/PAW) results for the four-layer slab.

\begin{tabular}{lcccc} 
Adsorption site & & $\begin{array}{c}\text { Adsorption } \\
\text { energy }(\mathrm{eV})\end{array}$ & $\begin{array}{l}\text { Pt-O bond } \\
\text { length }(\AA)\end{array}$ & $\begin{array}{c}\text { O-O bond } \\
\text { length }(\AA)\end{array}$ \\
\hline Hollow & hcp & -0.46 & 1) $2.31 \times 2$ & 1.38 \\
(111) & fcc & -0.52 & 2) 2.05 & \\
Bridge (111) & & -0.63 & $2.06 \times 2$ & 1.36 \\
Bridge (100) & -1.02 & $2.02 \times 2$ & 1.37 \\
Short bridge (110) & -1.58 & $1.99 \times 2$ & 1.38 \\
Long bridge (110) & -1.07 & $2.03 \times 2$ & 1.37
\end{tabular}




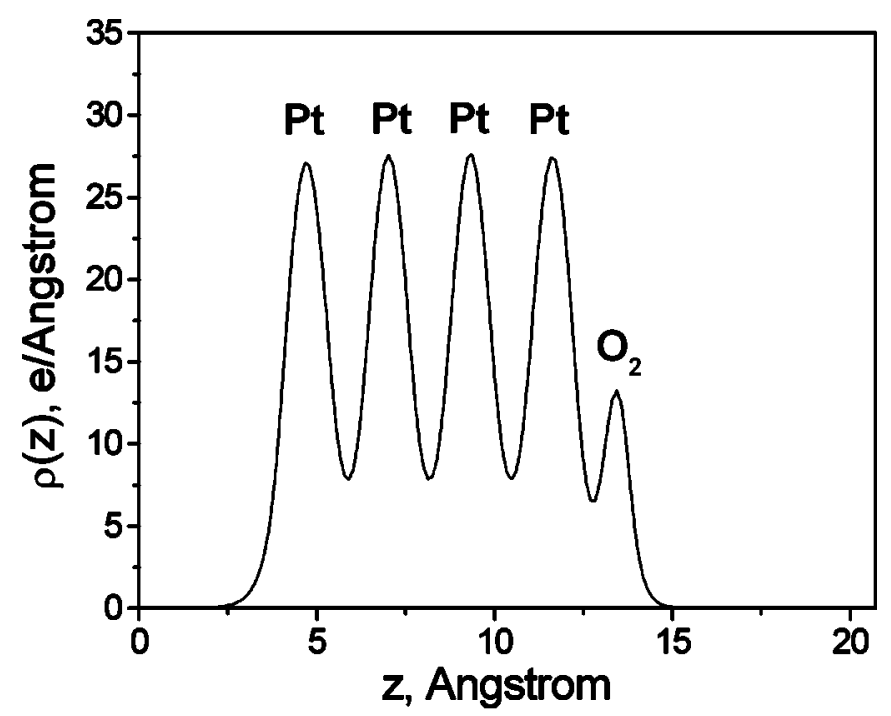

(a)

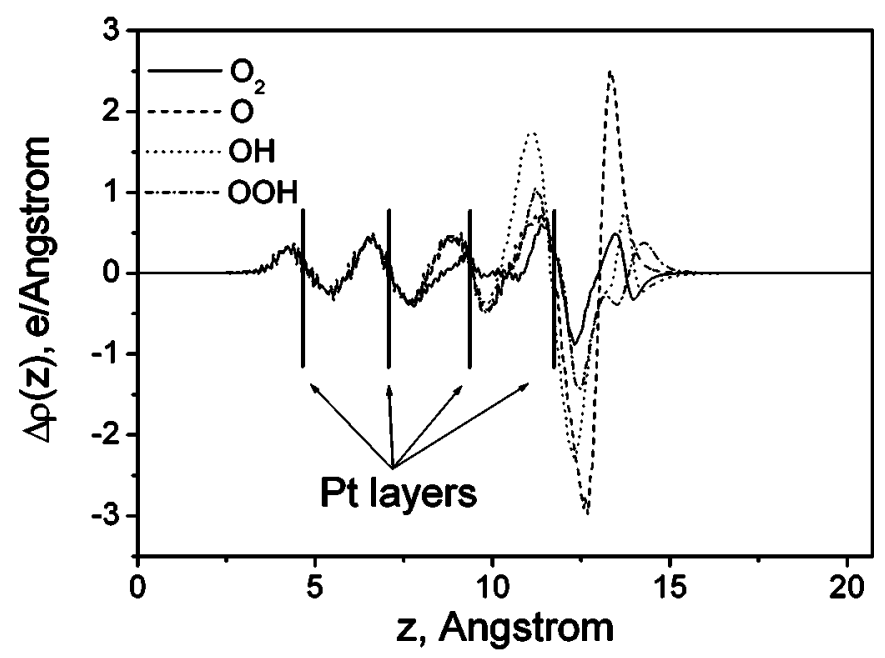

(b)

Figure 3. (a, top) Electron charge density profile of the oxygen molecule adsorbed on the $\mathrm{Pt}(111)$ surface at the hollow position. (b, bottom) Chargetransfer functions for $\mathrm{O}_{2}, \mathrm{O}, \mathrm{OOH}$, and $\mathrm{OH}$ adsorbed on $\mathrm{Pt}(111)$ surface. Adsorbed species are observed at 13.0-14.0 $\AA$, the Pt slab at 4.7-11.9 $\AA$. Positive values correspond to an excess electron density (i.e., negative charge) at given coordinates.

index planes of platinum, suggesting that it is the preferred adsorption site on a polycrystalline Pt substrate.

In addition to obtaining geometries and total energies, DFT results also include the electronic charge density, $\rho_{\mathrm{e}}(z)$, which has the sign convention of being more positive where the density of electrons is higher. Figure 3a shows the electronic charge density of the $\mathrm{O}_{2}$ - $\mathrm{Pt}$ system with oxygen adsorbed at the hollow position. The two oxygen atoms are both contained in the peak at $13.5 \AA$.

For a better understanding of the charge transfer and distribution and the formation of the bond it is useful to subtract the charge densities for the slab and isolated species from the charge densities of the adsorbed systems. For example, for the oxygen molecule the charge transfer function is defined as

$$
\Delta \rho_{\mathrm{e}}(z)=\left\{\rho_{\mathrm{e}}(z) / \mathrm{O}_{2} \operatorname{Pt}(111)-\rho_{\mathrm{e}}(z) / \mathrm{O}_{2}-\rho_{\mathrm{e}}(z) / \mathrm{Pt}(111)\right\}
$$

where $\rho_{\mathrm{e}}(z) / \mathrm{O}_{2} \mathrm{Pt}(111)$ is the electron density of the system with the adsorbed oxygen molecule, $\rho_{\mathrm{e}}(z) / \mathrm{O}_{2}$ is the electron density of isolated $\mathrm{O}_{2}$ with its positions fixed to those in its adsorbed state, and $\rho_{\mathrm{e}}(z) / \mathrm{Pt}(111)$ is the electron density of the $\mathrm{Pt}(111)$ slab. Figure $3 \mathrm{~b}$ shows the charge-transfer functions for several oxygen-containing species on the $\operatorname{Pt}(111)$ surface. For all species the charge is transferred from the Pt slab to the adsorbed species and shows a polarization and an oscillatory behavior that is considerably, but not completely, damped out over four layers. It is expected that oscillations would damp out the further we enter the metal. The oscillation damping behaves equally for all species after the third Pt layer, but in contrast to other adsorbates the oscillation order for the adsorbed oxygen molecule is broken in the first two layers.

In order to investigate the dependence of the system properties on the electric field, optimized geometries were taken from the VASP results and applied to those on a $\mathrm{Pt}_{9}(111)$ cluster and reoptimized again. Figure 4a displays the $\mathrm{O}-\mathrm{O}$ bond length of $\mathrm{O}_{2}$ adsorbed on the $\mathrm{Pt}_{9}(111)$ cluster at the hollow and bridge positions as a function of applied electric field. As expected, the O-O bond length decreases with increasing field for both the hollow and bridge positions, but the dependence is more pronounced for the bridge adsorption site, where $\mathrm{O}_{2}$ is more strongly adsorbed.

The distances between oxygen atoms of the adsorbed $\mathrm{O}_{2}$ molecule and the nearest $\mathrm{Pt}$ atoms of the $\mathrm{Pt}_{9}(111)$ cluster are plotted as a function of applied electric field in Fig. 4b. The increasing electric field pushes the molecule away from the surface. This fielddependent displacement is relatively moderate for the hollow position, but the bridge position, by contrast, reveals a much more pronounced field dependence.

Figure $4 \mathrm{c}$ shows natural atomic charges of the oxygen atoms for the $\mathrm{O}_{2}$ molecule adsorbed at the hollow and bridge positions on the $\mathrm{Pt}_{9}(111)$ cluster as a function of applied electric field. In general, the oxygen molecule at the hollow position bears a more negative charge than at the bridge position, suggesting that oxygen in the hollow position is more polarized. This is in a good agreement with associating the $\mathrm{O}_{2}$ at the hollow position to a peroxo-like $\left(\mathrm{O}_{2}^{2-}\right)$ state and $\mathrm{O}_{2}$ at the bridge position to a superoxo-like $\left(\mathrm{O}_{2}^{-}\right)$state. The charge from the d orbitals of the Pt atoms is transferred mostly to the $2 \pi^{*}$ orbital of the adsorbed $\mathrm{O}_{2}$ molecule. Without an applied electric field the difference between $2 \mathrm{p}$ populations of oxygen atoms in the $\mathrm{O}_{2}$ molecule in the gas phase and adsorbed on the Pt surface amounts to -0.19 a.u. for the bridge position per $\mathrm{O}$ atom and -0.31 and -0.26 a.u. for the $\mathrm{O}$ atoms in $\mathrm{O}_{2 \text { ads }}$ at the hollow position. The more negative value corresponds to the $\mathrm{O}$ atom lying closer to the $\mathrm{Pt}$ surface.

The electric field dependence of the charge transfer in the case of the bridge position is more pronounced than for the hollow position, showing that the polarizability of $\mathrm{O}_{2}$ at the bridge position is higher. For the peroxo-like oxygen at the hollow position it is apparently more difficult to accept more electrons with decreasing electric field, which may be related to the fact that the $2 \pi^{*}$ orbital is saturated for this species, but the superoxo-like oxygen at the bridge position can still accept charge. Decreasing the electric field leads to an electron transfer to the adsorbed $\mathrm{O}_{2}$ molecule and to an increase of the antibonding $2 \pi^{*}$ orbital population. As a result, the O-O bond weakens, and finally the $\mathrm{O}_{2}$ molecule will dissociate on the surface. Figure $4 \mathrm{~d}$ shows the $\mathrm{O}-\mathrm{O}$ stretching frequency in the $\mathrm{O}_{2 \text { ads }}$ molecule at the hollow and bridge positions on the $\mathrm{Pt}_{9}(111)$ cluster. A more negative field weakens the internal O-O bond shifting the frequency to a lower value for both adsorption sites. Again the field dependence for the bridge position is stronger, which we ascribe to the $2 \pi^{*}$ orbital not being saturated for the peroxo-like species adsorbed in the bridge position. The experimental values in the absence of an electric field are 690 and $870 \mathrm{~cm}^{-1}$ for the hollow and bridge positions, respectively, ${ }^{23}$ which compares reasonably well with our values on the $\mathrm{Pt}_{9}(111)$ cluster, $c a .740$ and $960 \mathrm{~cm}^{-1}$, respectively (Fig. 4d). Previous VASP calculations of the adsorbed oxygen molecule gave 690 and $850 \mathrm{~cm}^{-1}$, respectively. ${ }^{13}$

$O$ adsorption.- - The product of oxygen molecule dissociation in the gas phase under UHV conditions, atomic oxygen, is the most 


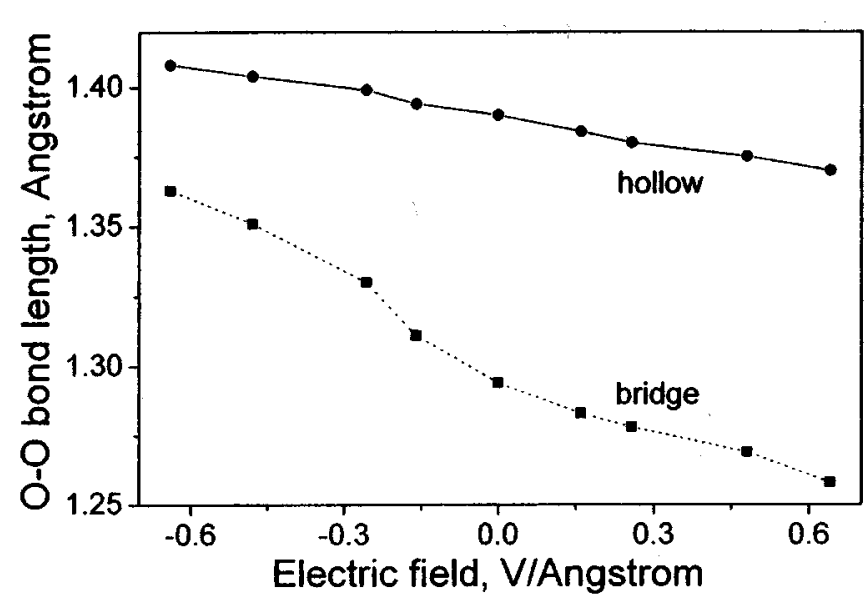

(a)

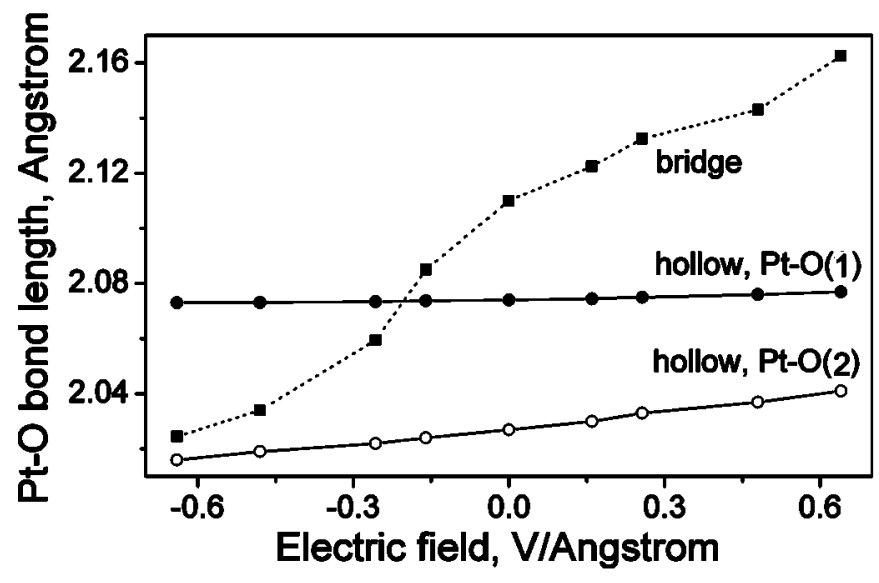

(b)

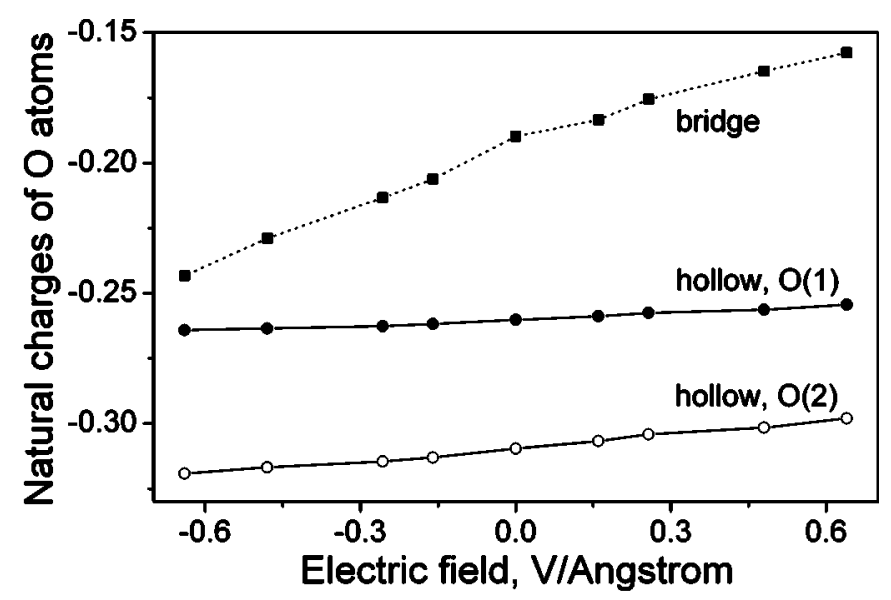

(c)

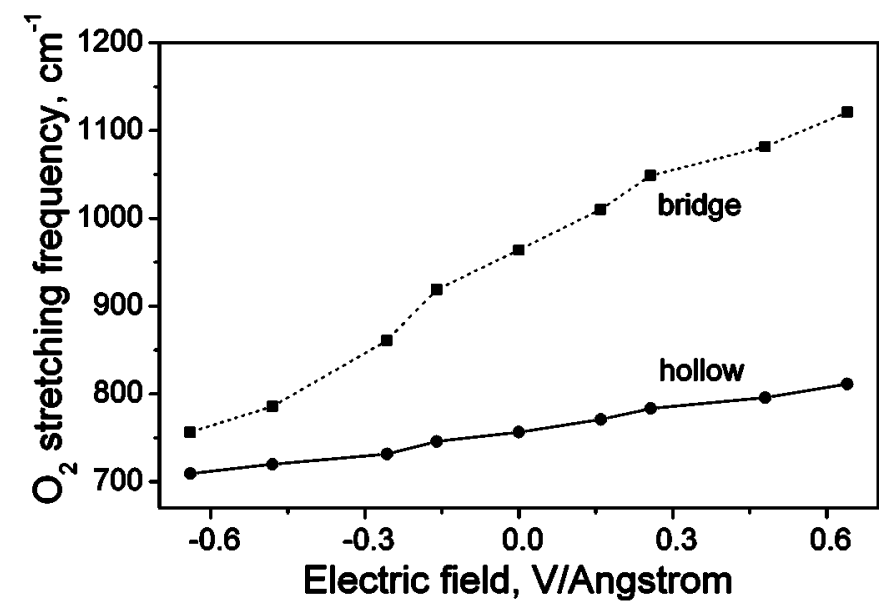

(d)

Figure 4. (a) Bond length in the $\mathrm{O}_{2}$ molecule adsorbed on $\mathrm{Pt}_{9}$ at the hollow and bridge positions as a function of the applied electric field. (b) Pt-O distances in the system $\mathrm{Pt}_{9}-\mathrm{O}_{2}$ for the hollow and bridge adsorption sites as a function of the applied electric field. O(2) lies closer to the Pt surface between two Pt atoms, $\mathrm{O}(1)$ is further away and is connected to only one Pt atom. (c) Natural atomic charges of the $\mathrm{O}$ atoms in the $\mathrm{O}_{2}$ molecule adsorbed on $\mathrm{Pt}_{9}$ cluster at the hollow and bridge positions as a function of the applied electric field. (d) $\mathrm{O}-\mathrm{O}$ stretching frequency of the $\mathrm{O}_{2}$ molecule at hollow and bridge positions as a function of the applied electric field.

stable configuration of oxygen on Pt surfaces. On the (111) surface atomic oxygen prefers the threefold hollow sites (Fig. 5a). On the (100) surface, the atom lies in the fourfold hollow between four Pt atoms (Fig. 5b), and only on the (110) surface the bridge position between two Pt atoms of the first layer (Fig. 5c) is preferred. Note that, interestingly, $\mathrm{Pt}(100)$ is the surface with the lowest affinity for atomic oxygen, although the difference with $\mathrm{Pt}(111)$ is small. Binding energies and distances of the adsorbed $\mathrm{O}$ atom in its most stable adsorption site on the three low index Pt surfaces are given in Table III.

Atomic oxygen serves as an acceptor of electron density from the Pt surface. The charge-transfer function shows a high polarization in the region of the Pt-O bond (Fig. $3 b$ ), providing evidence for the fact

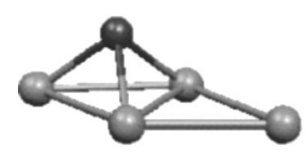

a)

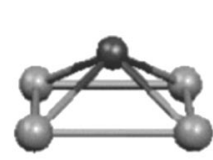

b)

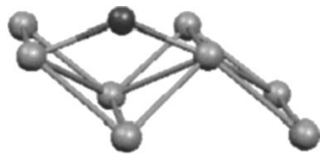

c)
Figure 5. Atomic oxygen adsorbed on low index Pt surfaces: (a) hollow position on (111), (b) hollow position on (100), (c) bridge position on (110). that the bond has predominantly ionic character, which is consistent with the previous theoretical studies of the system. ${ }^{60-62}$ In comparison to the gas phase, the oxygen atom on the $\mathrm{Pt}_{9}(111)$ cluster loses 0.04 a.u. of charge of its 2 s population, but accepts 0.75 a.u. to its $2 p$ population.

The electric field dependence of the $\mathrm{O}_{\text {ads }}$ properties were investigated for the $\mathrm{Pt}_{9}(111)-\mathrm{O}$ system, where atomic oxygen lies in the threefold hollow position. The dependence of the Pt-O distance on the applied electric field is shown in Fig. 6a. Negative electric fields lead to an elongation of the surface-O distance, in good agreement with previous studies. ${ }^{60,63}$ The decrease of the applied field from

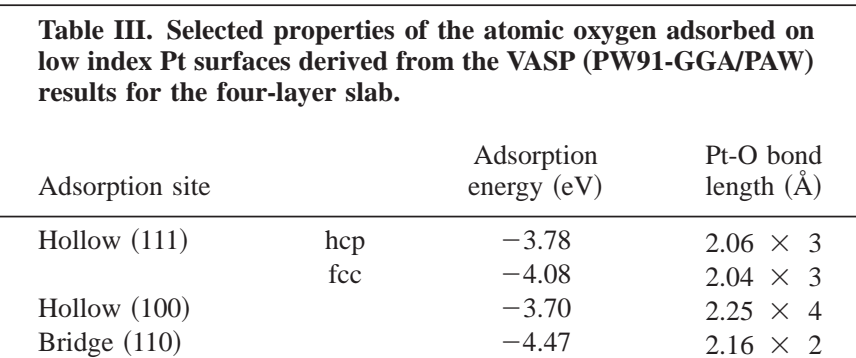




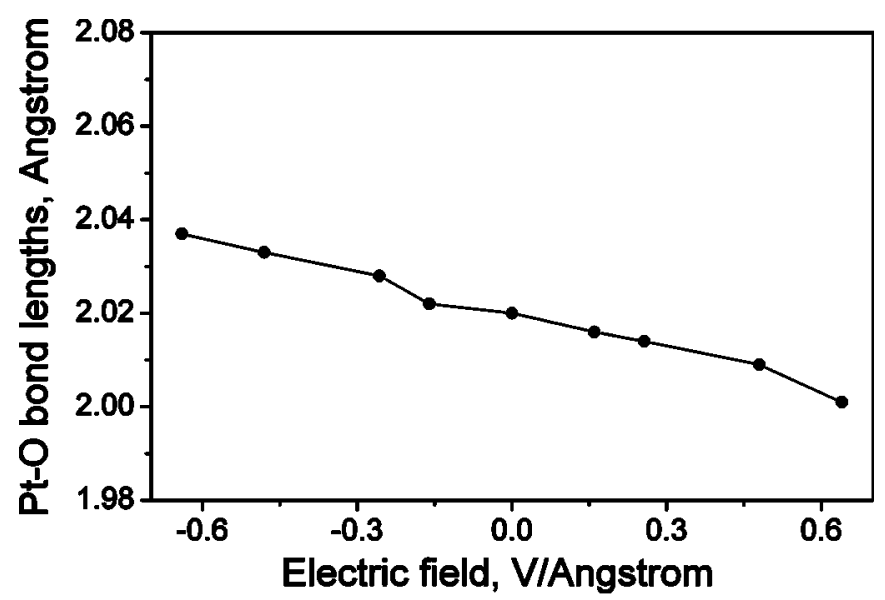

(a)

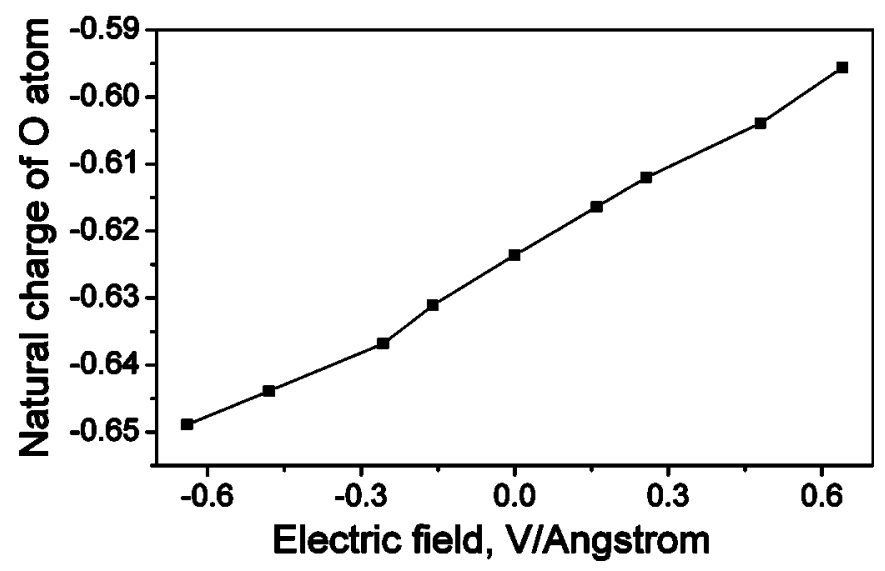

(b)

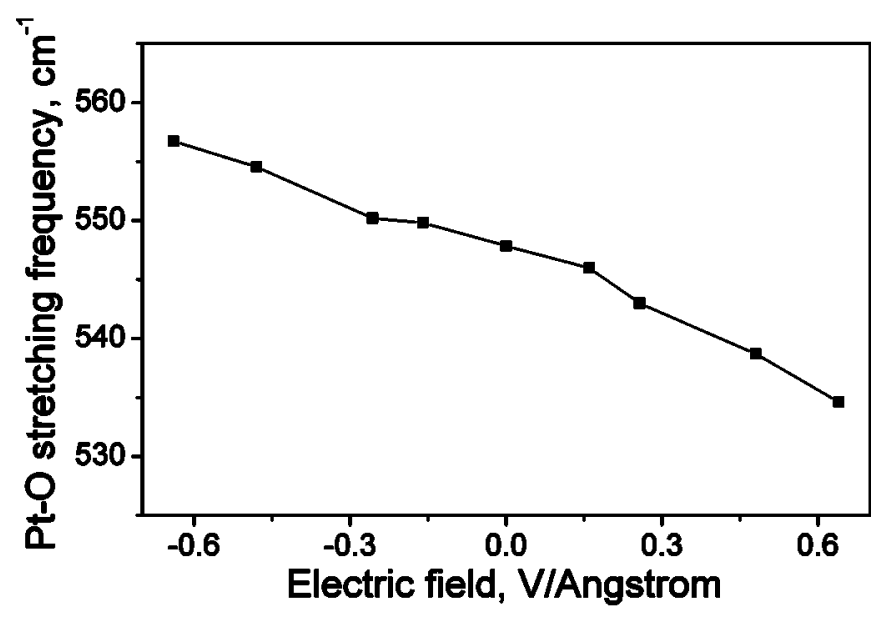

(c)

Figure 6. (a) $\mathrm{Pt}-\mathrm{O}$ distance in the system $\mathrm{Pt}_{9}-\mathrm{O}$ for the hollow adsorption site as a function of the applied electric field. (b) Natural atomic charge of the $\mathrm{O}$ atom adsorbed on $\mathrm{Pt}_{9}$ cluster at the hollow position as a function of the applied electric field. (c) Pt-O frequency for the $\mathrm{O}$ atom at the hollow position as a function of the applied electric field.

+0.64 to $-0.64 \mathrm{~V} / \AA \AA$ has a small influence on the geometry of the $\mathrm{O}_{\text {ads }}$ on the $\mathrm{Pt}_{9}$ cluster and is accompanied by a moderate increase of the natural atomic charge, which reaches a value of -0.65 a.u. for $-0.64 \mathrm{~V} / \AA$ (Fig. 6b). The Pt-O stretching frequency is shown in Fig. 6c. The frequency increases with decreasing field, but the shift is relatively moderate and lies within $15 \mathrm{~cm}^{-1}$. The negative slope of

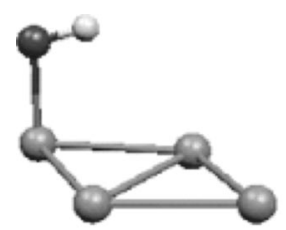

a)

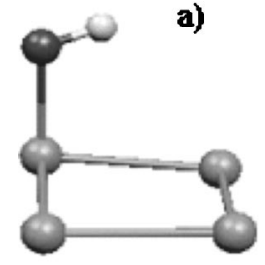

d)

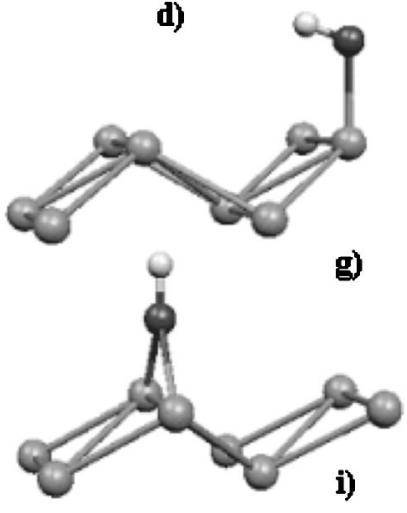

i)

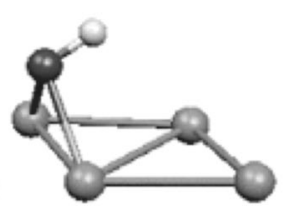

b)

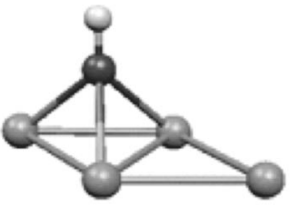

c)

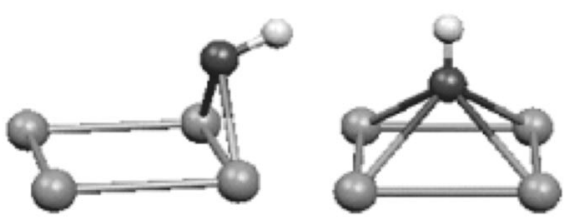

f)

e)

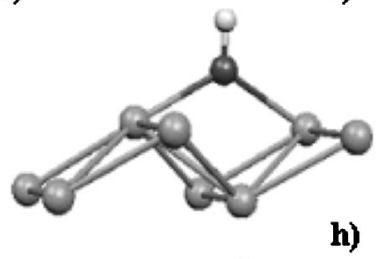

h)
Figure 7. Hydroxyl adsorbed on low index Pt surfaces: (a) atop on (111), (b) bridge on (111), (c) hollow on (111), (d) atop on (100), (e) bridge on (100), (f) hollow on (100), (g) atop on (110), (h) long bridge on (110), (i) short bridge on (110), (j) hollow on (110).

Fig. 6c also indicates that $\mathrm{O}$ forms an anionic bond to the platinum surface. ${ }^{64,65}$ The smallness of the slope is presumably related to the small polarizability of the bond.

$\mathrm{OH}$ adsorption.-The $\mathrm{OH}$ radical is one of the most important intermediates of the ORR and is formed in large amounts during the processes of oxygen reduction and water oxidation. Hydroxyl chemisorption was examined at a surface coverage of 1/4 ML for all three low index Pt surfaces. Earlier theoretical studies of the system showed that $\mathrm{OH}$ binds quite strongly at coverages from 1/9 to $1 \mathrm{ML}$ and has an adsorption energy between -2.20 and $-2.53 \mathrm{eV}^{31} \mathrm{At}$ 1/4 ML coverage $\mathrm{OH}$ adsorbs preferentially at the top and bridge positions (Fig. 7a and b). The third site, with $\mathrm{OH}$ bond between three Pt atoms in the hollow position (Fig. 7c), is less favorable.

On the (100) surface three adsorption sites were studied. In this case the most stable one is the bridge position between two $\mathrm{Pt}$ atoms (Fig. 7e), followed by the top and hollow positions (Fig. 7d and f).

On the (110) surface, four sites for $\mathrm{OH}$ adsorption were studied. As with the (111) surface, the top position (Fig. 7g) has the highest adsorption energy of $-2.71 \mathrm{eV}$. OH adsorbs also between two $\mathrm{Pt}$ atoms of the first layer at the long bridge and short bridge positions (Fig. 7h and i). The hollow position between four Pt atoms in the first layer and one Pt atom in the second layer (Fig. 7j) is less stable with an adsorption energy of $-1.55 \mathrm{eV}$. Some selected properties of the adsorbed $\mathrm{OH}$ radicals are given in Table IV.

A remarkable conclusion from the results in Table IV in comparison to Table III is that, whereas the oxygen atom adsorbs weakest on $\mathrm{Pt}(100)$, the hydroxyl species adsorbs strongest on $\mathrm{Pt}(100)$. As mentioned in the introduction, $\mathrm{Pt}(100)$ is also the surface which is the least active for the ORR in alkaline and perchloric acid media.

Figure $3 b$ shows the charge-transfer function for the hydroxyl radical adsorbed at the top position of the (111) surface. Here, $\mathrm{OH}$ is predicted to act as an acceptor of electron density from Pt. 
Table IV. Selected properties of the hydroxyl adsorbed on lowindex Pt surfaces derived from the VASP (PW91-GGA/PAW) results for the four-layer slab.

\begin{tabular}{lccc} 
Adsorption site & $\begin{array}{c}\text { Adsorption } \\
\text { energy (eV) }\end{array}$ & $\begin{array}{l}\text { Pt-O bond } \\
\text { length }(\AA)\end{array}$ & $\begin{array}{c}\text { O-H bond } \\
\text { length }(\AA)\end{array}$ \\
\hline Atop (111) & -2.23 & 1.99 & 0.983 \\
Bridge (111) & -2.14 & $2.19 \times 2$ & 0.983 \\
Hollow (111) & -1.80 & $2.23 \times 3$ & 0.976 \\
Atop (100) & -2.38 & 1.98 & 0.980 \\
Bridge (100) & -2.74 & $2.11 \times 2$ & 0.981 \\
Hollow (100) & -2.02 & $2.41 \times 4$ & 0.983 \\
Atop (110) & -2.71 & 1.98 & 0.980 \\
Long Bridge (110) & -2.25 & $2.28 \times 2$ & 0.980 \\
Short Bridge (110) & -2.53 & $2.09 \times 2$ & 0.975 \\
Hollow (110) & -1.55 & $1) 2.76 \times 4$ & 0.984 \\
& & $2) 2.63$ &
\end{tabular}

In the cluster calculations, the $\mathrm{OH}$ radical adsorbed on the $\mathrm{Pt}_{9}$ (111) cluster accepts a charge of 0.26 a.u. from the $\mathrm{Pt}$ atoms, with the hydrogen atom losing 0.07 a.u. of its 1 s population, the $2 \mathrm{~s}$ population of the $\mathrm{O}$ atom decreasing by 0.06 a.u., and the $2 \mathrm{p}$ population, in contrast, increasing by 0.39 a.u. The molecular orbital involved in the charge transfer is $1 \pi^{*}$ of the $\mathrm{OH} .{ }^{60}$

The electric field dependence of the Pt-OH bond is shown in Fig. 8a. In contrast to the $\mathrm{Pt}_{9}-\mathrm{O}_{2}$ system, in the case of adsorbed $\mathrm{OH}$ the bond becomes longer for the more negative field. Both, the $\mathrm{O}$ and $\mathrm{H}$ atoms become more negatively charged (Fig. 8b). Figure 8c shows $\mathrm{O}-\mathrm{H}$ and $\mathrm{Pt}-(\mathrm{OH})$ stretching frequencies of the hydroxyl adsorbed on a $\mathrm{Pt}_{9}(111)$ cluster as a function of applied electric field. At zero electric field $\mathrm{O}-\mathrm{H}$ stretching frequency in the $\mathrm{OH}$ radical adsorbed on $\mathrm{Pt}(111)$ surface is $c a .3722 \mathrm{~cm}^{-1}$, in a good agreement with an experimental value of $3735 \mathrm{~cm}^{-1}{ }^{28}$ The increase of the electron transfer from the $\mathrm{Pt}$ to $\mathrm{OH}_{\text {ads }}$ with more negative field weakens the internal $\mathrm{O}-\mathrm{H}$ bond and as a result the $\mathrm{O}-\mathrm{H}$ frequency decreases. The $\mathrm{Pt}-(\mathrm{OH})$ stretching frequency decreases as well, as the $\mathrm{OH}_{\text {ads }}$ is pushed away from the surface.

$\mathrm{OOH}$ adsorption.-The adsorption properties of another intermediate of oxygen reduction, the $\mathrm{OOH}$ superoxide radical, were also studied. Sidik et al. calculated an activation energy for $\mathrm{OOH}$ dissociation on $\mathrm{Pt}_{2}$ of $0.06 \mathrm{eV}$. The activation energy remained small for larger Pt clusters. ${ }^{6}$

It was found that on a (111) surface the only stable configuration is the bridge position between two Pt atoms (Fig. 9). OOH has an adsorption energy of $-1.07 \mathrm{eV}$. The Pt-O distances are 2.03 and $2.64 \AA$. The larger distance corresponds to the $\mathrm{H}$-bonded $\mathrm{O}$ atom. The $\mathrm{O}-\mathrm{O}$ and $\mathrm{O}-\mathrm{H}$ bond lengths are 1.45 and $0.99 \AA$, respectively. On (100) and (110) surfaces the radical was found to be unstable and dissociated into $\mathrm{OH}_{\text {ads }}$ and $\mathrm{O}_{\text {ads }}$.

The charge-transfer function of the superoxide radical adsorbed on the (111) surface is shown in Fig. 3b. The charge is transferred from the Pt slab to the adsorbed radical which acts as an acceptor of electron density.

The properties of the adsorbed superoxide radical on the $\mathrm{Pt}_{9}(111)$ cluster as a function of the applied electric field are similar to those of the oxygen molecule. The O-O bond length in the adsorbed radical increases with decreasing electric field up to almost $1.39 \AA$ (Fig. 10a), compared to $1.33 \AA$ for the uncoordinated species in the gas phase. At the same time the radical moves closer to the Pt surface, i.e., the Pt-O bond length decreases. The field dependence of the $\mathrm{O}-\mathrm{H}$ bond length is not so pronounced. With decreasing field from +0.64 to $-0.64 \mathrm{~V} / \AA$ the $\mathrm{O}-\mathrm{H}$ bond shortens from 0.99 to 0.98 $\AA$ compared to $0.98 \AA$ in the gas phase.

Adsorption of the superoxide radical on the Pt surface causes charge transfer and redistribution in the whole system. The charge is transferred from the d orbitals of the Pt atoms, mostly to the $2 p$ orbitals of the $\mathrm{O}$ atoms. Compared to the gas phase the population of

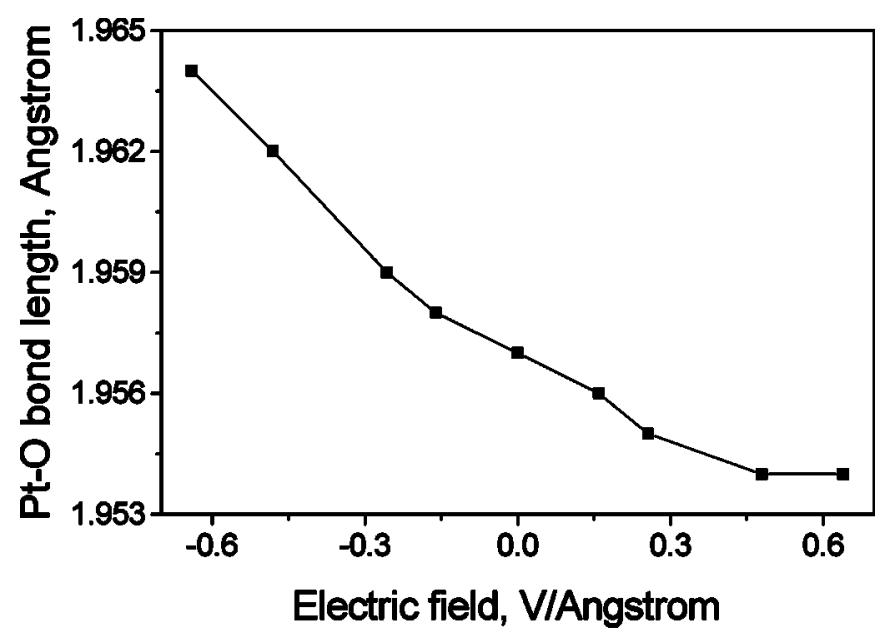

(a)

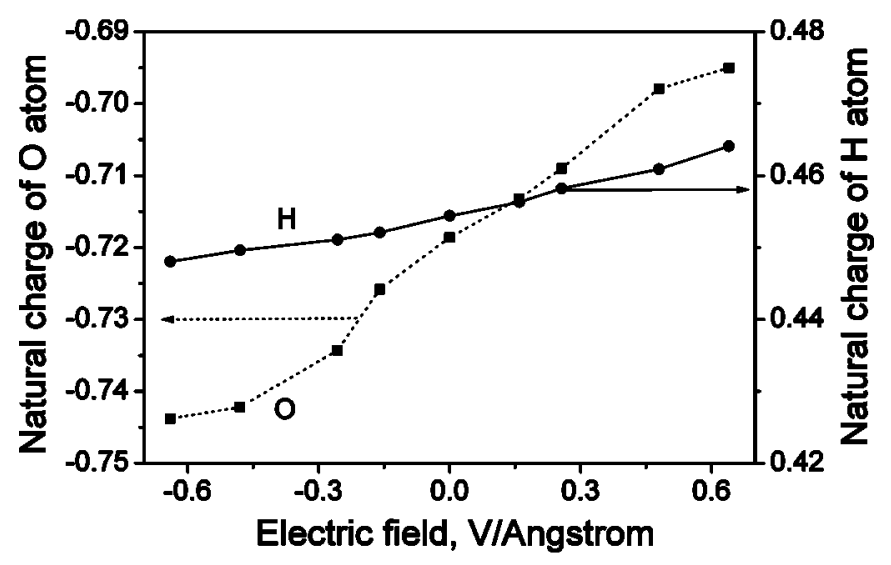

(b)

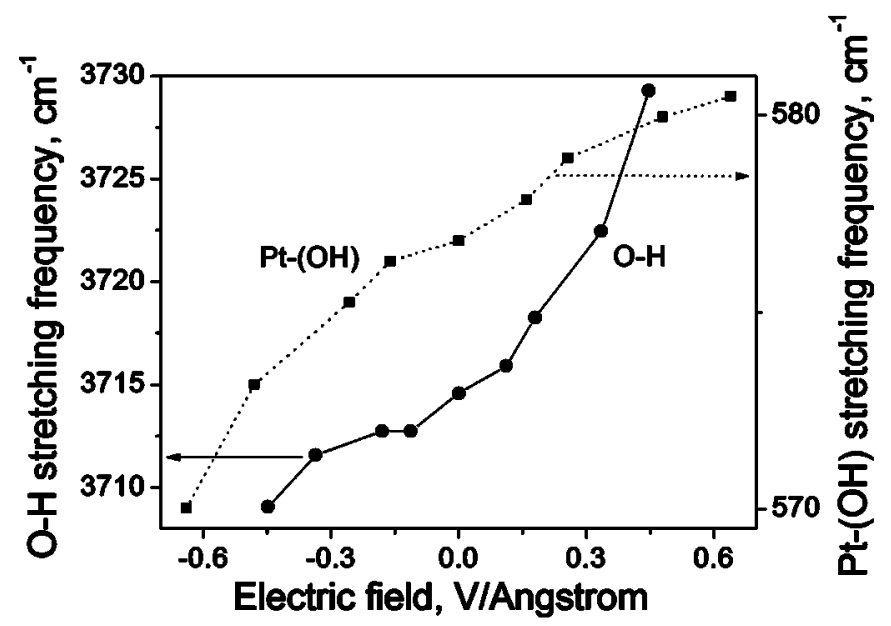

(c)

Figure 8. (a) $\mathrm{Pt}-\mathrm{O}$ distance in the system $\mathrm{Pt}_{9}-\mathrm{OH}$ for the atop adsorption site as a function of the applied electric field. (b) Natural atomic charges of the $\mathrm{O}$ and $\mathrm{H}$ atoms in hydroxyl adsorbed on $\mathrm{Pt}_{9}$ cluster at the atop position as a function of the applied electric field. (c) $\mathrm{O}-\mathrm{H}$ and $\mathrm{Pt}-\mathrm{OH}$ stretching frequencies of the $\mathrm{OH}$ adsorbed on $\mathrm{Pt}_{9}$ cluster at the atop position as a function of the applied electric field.

$2 p$ orbitals of the oxygen atoms without applied electric field increases by 0.15 and 0.04 a.u., the latter value corresponding to the $\mathrm{H}$-bonded $\mathrm{O}$ atom. At the same time the hydrogen atom loses 0.05 a.u. of its $1 \mathrm{~s}$ population and becomes more positively charged. 


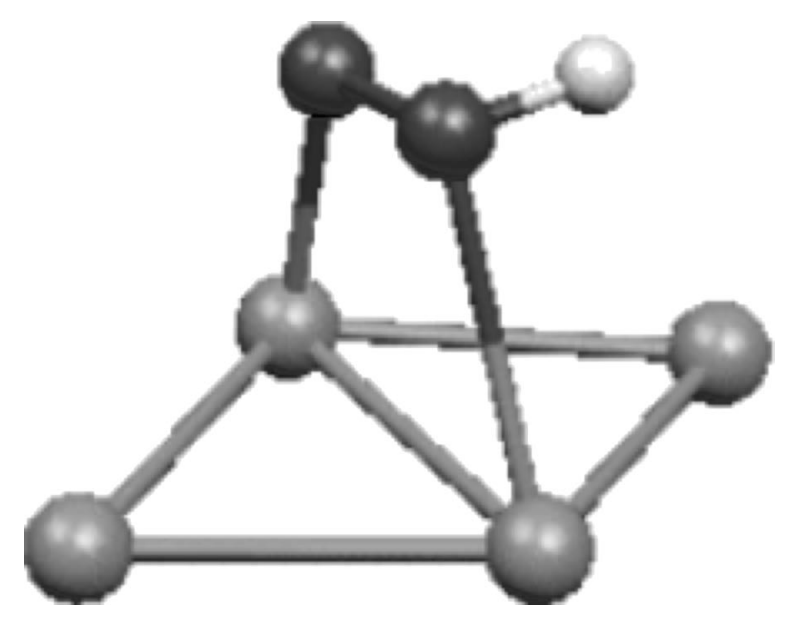

Figure 9. OOH adsorbed at the bridge position on the $\mathrm{Pt}(111)$ surface.

Figure 10b depicts the natural atomic charges of the $\mathrm{O}$ atoms in the adsorbed superoxide radical as a function of applied electric field. The H-bonded oxygen atom bears a more negative charge than the other oxygen and has a more pronounced field-dependent charge transfer. As a result of the charge transfer the $\mathrm{O}-\mathrm{O}$ and $\mathrm{O}-\mathrm{H}$ stretching frequencies decrease with more negative field (Fig. 10c). These frequencies for the uncoordinated species in the gas phase have been calculated to be 1115 and $3467 \mathrm{~cm}^{-1}$, respectively (experimental values are 1097.6 and $3436.2 \mathrm{~cm}^{-166}$ ).

$\mathrm{H}_{2} \mathrm{O}_{2}$ adsorption.- It is well known that during oxygen reduction, hydrogen peroxide can be formed as a product or intermediate product on low index Pt surfaces. ${ }^{8,35}$ Therefore, adsorption properties of $\mathrm{H}_{2} \mathrm{O}_{2}$ on (111), (100), and (110) surfaces were investigated, but in our calculations $\mathrm{H}_{2} \mathrm{O}_{2}$ was unstable and dissociated into two adsorbed hydroxyls on all three low index Pt surfaces. A second possibility for $\mathrm{H}_{2} \mathrm{O}_{2}$ decomposition is the formation of a water molecule and an $\mathrm{O}$ atom. Both paths and their relevance for fuel cells are discussed in the following section.

Significance for the fuel cell reaction.-In the previous sections we have presented the results of periodic and cluster-based DFT studies of $\mathrm{O}_{2}, \mathrm{O}, \mathrm{OOH}, \mathrm{OH}$, and $\mathrm{H}_{2} \mathrm{O}_{2}$ adsorption and properties on three low-index Pt surfaces [(111), (100), and (110)] in order to obtain insight into the reduction mechanism of $\mathrm{O}_{2}$ under conditions relevant for PEMFCs. Oxygen reduction is one of the key processes in low-temperature fuel cells, and it has a great impact on the performance, stability, and reliability of the entire fuel cell system.

From our VASP adsorption energies we can construct the energetic pathways of the reaction on Pt. These adsorption energies were obtained in the absence of an electric potential, and would formally correspond to the potential of zero total charge. Figure 11a-c show energy diagrams of water formation on three low index surfaces. The calculations use one oxygen and two hydrogen molecules in the gas phase and a relaxed Pt surface as the reference, and we keep this stoichiometry throughout the reaction. For these diagrams the adsorption energies of molecular hydrogen were calculated to be $-0.88,-1.17$, and $-0.14 \mathrm{eV}$ for (111), (100), and (110) surfaces, respectively. It depends on the electrochemical potential of the anode and is therefore somewhat semantic whether the adsorbed species is called atomic hydrogen or a proton. At the cathode we followed the policy to calculate only the neutral adsorbates, i.e., each reduction step was accompanied by protonation. At the relevant cathode potentials, the oxygen species presumably reacts directly with a proton (or hydronium ion) from solution rather than with adsorbed hydrogen. The effects of solvation or interactions with counterions are not considered at this stage.

In the first step we let the reactants adsorb on the Pt surface, whereby we assume that $\mathrm{H}_{2}$ adsorbs dissociatively and $\mathrm{O}_{2}$ molecu-

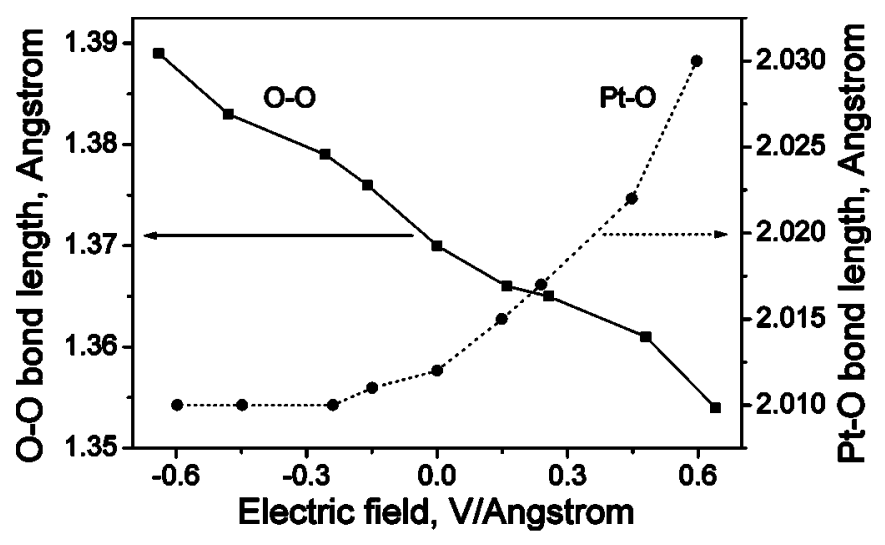

(a)

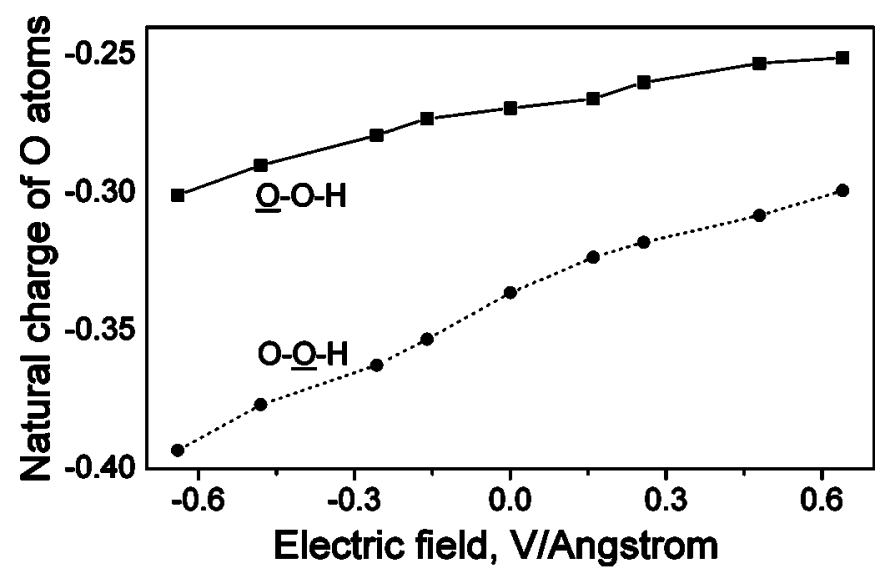

(b)

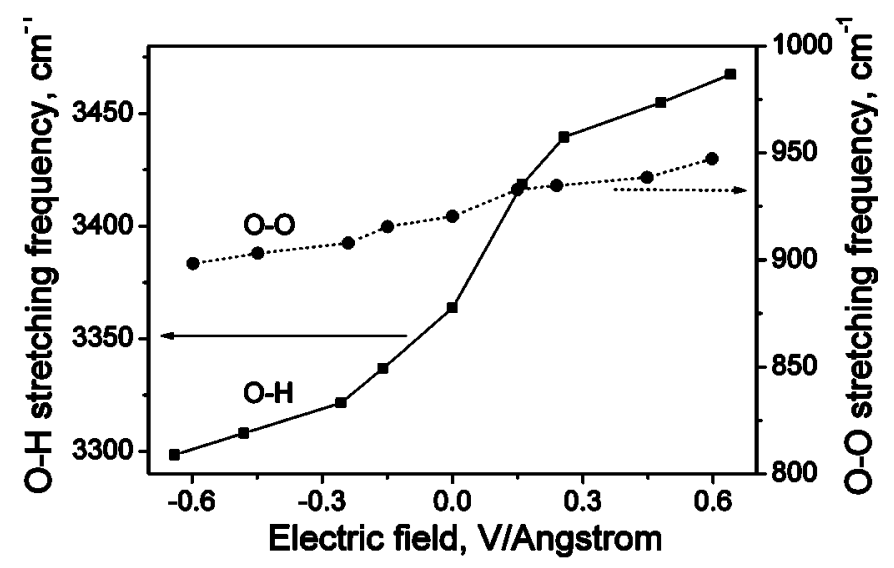

(c)

Figure 10. (a) $\mathrm{O}-\mathrm{O}$ and $\mathrm{Pt}-\mathrm{O}$ distances in the system $\mathrm{Pt}_{9}-\mathrm{OOH}$ for the bridge adsorption site as a function of the applied electric field. (b) Natural atomic charges of the $\mathrm{O}$ atoms in the superoxide radical adsorbed on $\mathrm{Pt}_{9}$ cluster at the bridge position as a function of the applied electric field. (c) O-O and $\mathrm{O}-\mathrm{H}$ stretching frequencies of the superoxide radical adsorbed on the $\mathrm{Pt}_{9}$ cluster at the bridge position as a function of the applied electric field.

larly. In the second step the oxygen molecule is reduced by one electron to form a superoxide OOH radical on the (111) (Fig. 11a) surface, and an atomic oxygen and a hydroxyl radical on the (100) and (110) surfaces (Fig. 11b and c). In homogeneous aqueous solution, the addition of the first electron to $\mathrm{O}_{2}$ is unfavorable by -0.33 $\mathrm{V}^{4}$ On all crystal faces considered here it is at least exothermal. After a two-electron reduction we have basically two possibilities, formation of two hydroxyl radicals or the formation of atomic oxy- 


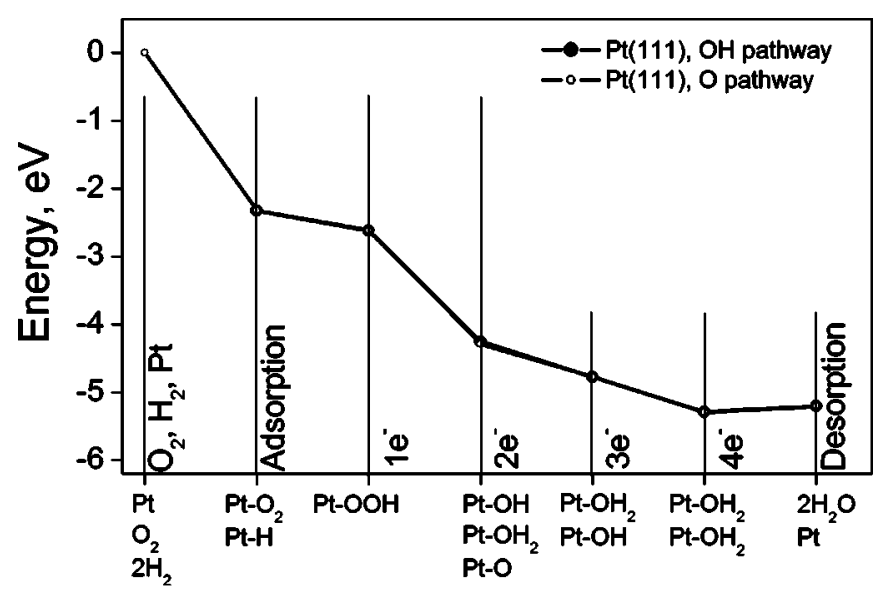

(a)

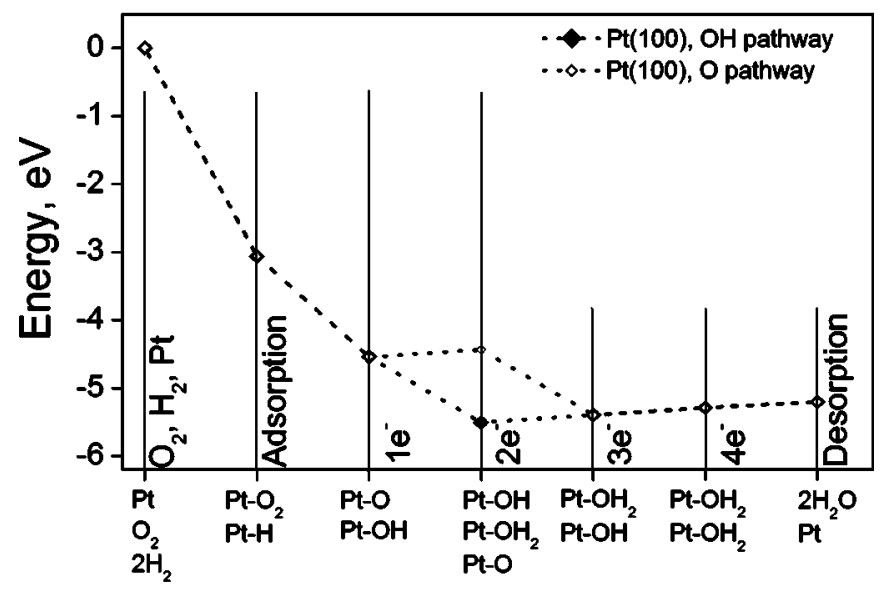

(b)

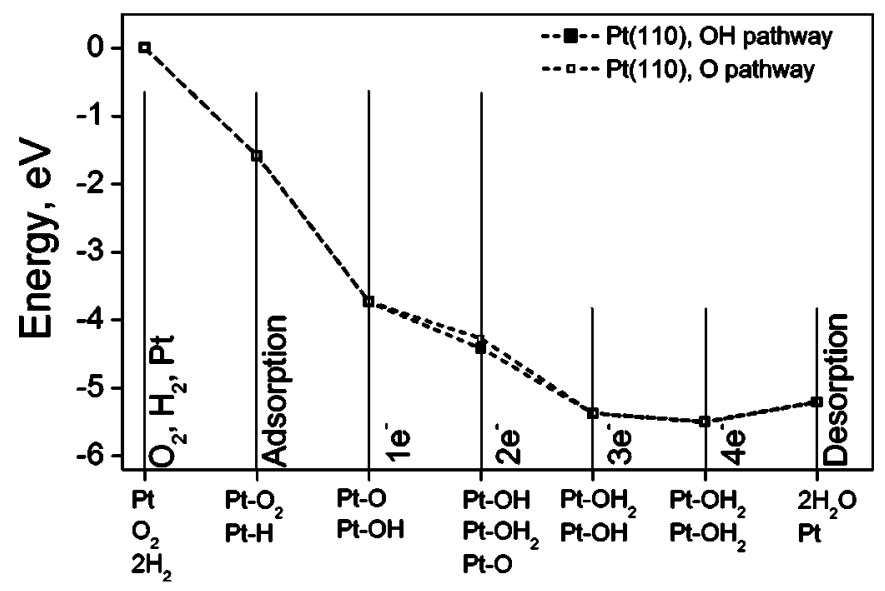

(c)

Figure 11. (a) Energy diagram of the oxygen reduction on $\operatorname{Pt}(111)$ surface. Intermediates of the reduction are shown on the horizontal axis. (b) Energy diagram of the oxygen reduction on $\mathrm{Pt}(100)$ surface. Intermediates of the reduction are shown on the horizontal axis. (c) Energy diagram of the oxygen reduction on $\mathrm{Pt}(110)$ surface. Intermediates of the reduction are shown on the horizontal axis.

gen and a water molecule. Note that at this point the O-O bond is already broken on all Pt surfaces. The possible formation of hydrogen peroxide is prevented by its instability on $\mathrm{Pt} . \mathrm{H}_{2} \mathrm{O}_{2}$ decays into hydroxyl radicals, or into atomic oxygen and a water molecule. As one can see in Fig. 11b and c, the former path is preferred for the
(100) and (110) surfaces, and only on the (111) surface both paths are energetically similar (Fig. 11a). The formation of hydroxyl radicals is very important for the fuel cell, since it is believed that the $\mathrm{OH}$ radical is the main agent that leads to membrane degradation. ${ }^{67}$

The $\mathrm{OH}$ radicals adsorb very strongly on the (100) surface (Table IV). This fact explains the energy increase in the following reduction steps on this surface. The surface is poisoned by the $\mathrm{OH}$ species, and this fact may reduce the activity dramatically. ${ }^{5,10}$ On the (111) and (110) surfaces the reduction can proceed more easily, decreasing the total energy without any hindrances with low activation energy. ${ }^{6}$ After the four-electron reduction we obtain the end product, water. This step is followed by water desorption from the Pt surface into the electrolyte. The desorption is entropically driven, at least when the product water is gas-phase water.

The calculated enthalpy of water formation amounts to -250.8 $\mathrm{kJ} \mathrm{mol}^{-1}$. This is in good agreement with the experimental value of $-241.8 \mathrm{~kJ} \mathrm{~mol}^{-1}$. Because of the decrease of the number of gas molecules the overall entropy decreases in the fuel cell reaction. This is mostly translational entropy. After the adsorption step this translational entropy is already lost, and $\Delta H$ should be very close to $\Delta G$ for each catalytic step.

Figure 11a-c were constructed in order to compare relative activities of the three low index Pt surfaces in the ORR because it is considered to be a convenient overall means of comparison. According to the present study, the best surface for the oxygen reduction seems to be the (111) facet, since it produces a continuous decrease in energy, with no minimum. The (110) surface should have a similar activity, but the (100) surface should have a reduced activity because of the strong adsorption of $\mathrm{OH}$ species. Experimental results in alkaline and perchloric acid media support this proposal. ${ }^{10}$

The presence of electric potentials on the electrochemical interfaces gives rise to nonspecific electrostatic effects for adsorbed species upon surface bonding. ${ }^{68}$ Electric potentials influence the properties of adsorbed species and can also control chemical reactions on the electrode surface. Thus, it was shown recently that for a PEMFC which was fed directly with reformed hydrogen in the presence of $\mathrm{CO}$, increasing the anode potential to values at which $\mathrm{CO}$ is oxidized to $\mathrm{CO}_{2}(0.6 \mathrm{~V})$, led to a significant increase of the fuel cell performance because the poisoned catalyst surface was cleaned during the applied current pulses. ${ }^{69}$ It is therefore of principal importance to study the effects of electrode potential on the properties of adsorbed reactants and intermediates (oxygen molecule and oxygencontaining species in our case) to understand and control electrochemical processes on the electrode surface.

Electrode potentials different from the potential of zero (total) charge (pztc) were modeled by an electric field perpendicular to the Pt surface. For a double layer of approximately $3 \AA$ thickness the range of applied fields corresponds to potentials in the range of -1.92 to $+1.92 \mathrm{~V} v s$. the potential of zero charge. It was shown previously that a double-layer thickness of $3 \AA$ gives very good agreement of the experimental Stark tuning slopes for $\mathrm{CO}$ adsorbed on Pt electrodes in aqueous electrolyte with the calculated ones. ${ }^{19,70}$ Nevertheless, the presence of interspersed Nafion chains and the proximity of three-phase boundaries in real fuel cells could affect the effective dielectric potential and therefore the double-layer thickness locally.

Furthermore, the thickness of the double layer can be affected by the potential itself: the larger the difference between the electrode potential and the potential of zero charge is, the smaller is the Debye-Hückel length. ${ }^{71}$

The mentioned electric potential limits will adjust depending on the variation of the double-layer thickness and the local dielectric constant. The natural limits will be determined by the reactions of the solvent, and this range will normally be narrower than the one used in the present calculations. The electric field intensities employed in our study are therefore believed to cover most of the cases which can arise for oxygen reduction on $\mathrm{Pt}$ in a fuel cell.

The presence of an electric potential affects the geometries, charges, and adsorption energies of the species on a catalyst surface 
quite dramatically. When a current is drawn from the fuel cell the anode potential is changed to more positive values, whereas the cathode potential is changed negatively. It means that in our fielddependent calculations we go from positive electric fields toward negative ones. With more negative potential, the oxygen molecule moves closer to the $\mathrm{Pt}$ surface, with the $\mathrm{O}-\mathrm{O}$ bond getting weaker as can be seen from the O-O bond length (Fig. 4a) and stretching frequency (Fig. 4d). The population of the antibonding $\pi^{*}$ orbital increases. These conditions should facilitate the O-O bond breaking. The same is applicable for the $\mathrm{O}-\mathrm{O}$ bond in the $\mathrm{OOH}$ radical. It is interesting to note that for the adsorbed oxygen atom negative fields make the Pt-O bond stronger as can be seen from the Pt-O stretching frequencies (Fig. 6c). The $\mathrm{OH}$ radical moves away from the surface, even though the Pt- $(\mathrm{OH})$ frequency does not change much. One of the possible consequences is the fact that under heavy fuel cell loads the radical leaves catalyst surfaces more easily, and the degradation activity increases. Thus, we observed recently $\mathrm{OH}$ radicals during fuel cell operation in the formed water by means of the spintrapping technique. ${ }^{72}$

The results presented in this paper were obtained for UHV conditions, but when one studies electrochemical reactions, the electrode is in contact with liquid water, and under fuel cell conditions the catalyst is covered with $\mathrm{H}_{2} \mathrm{O}$ molecules to large extent. Radical intermediates formed during oxygen reduction can change their properties significantly, they even leave the surface of an electrocatalyst in the presence of water ${ }^{17,33}$ to recombine in bulk solution, or to participate in membrane degradation reactions. ${ }^{67}$

\section{Conclusions}

The adsorption properties of the oxygen molecule and intermediates of the ORR on the (111), (100), and (110) platinum surfaces were calculated in the DFT-GGA framework using periodic boundary conditions and a slab model of the Pt surface. The electric-field dependence of the adsorbate properties was studied using a cluster model of the adsorption system.

The oxygen molecule has two preferential adsorption sites on the (111) surface, which are the hollow and the bridge positions, with adsorption in a bridge fashion being the most favorable. $\mathrm{O}_{2}$ at the hollow position bears a more negative charge and is best referred to as a peroxo-like $\mathrm{O}_{2}^{2-}$ state. The charge transfer at the bridge position is smaller, therefore the oxygen molecule forms here a superoxo-like $\mathrm{O}_{2}^{-}$state. These assignments are also supported by the O-O internal vibrational frequencies in their respective adsorbed states. Even if the peroxo-like adsorbate is more polar, the superoxo-like adsorbate in the bridge position is found to be much more polarizable. This remarkable feature may be ascribed to the fact that in the peroxostate, the $2 \pi^{*}$ orbital is saturated with electrons, whereas in the superoxo-state, it may still accept electrons.

On the (100) and (110) surfaces, $\mathrm{O}_{2}$ adsorbs mostly at the bridge positions between two $\mathrm{Pt}$ atoms. The product of oxygen dissociation in the gas phase, atomic oxygen, lies in the threefold and fourfold hollows on the (111) and (100) surfaces, respectively. The bridge position is preferred for the (110) facet. The formation of $\mathrm{O}_{\text {ads }}$ via electrochemical oxygen reduction is not energetically beneficial in comparison to the formation of $\mathrm{OH}$ radicals. Probable formation of atomic oxygen after the first electron reduction and decay of the $\mathrm{OOH}\left(\mathrm{OO}^{-}\right)$radical, which could be stable only on the (111) surface at the bridge position, could be followed by the reaction with water molecules present on $\mathrm{Pt}$ to form two adsorbed hydroxyl radicals. ${ }^{73}$ But the most probable way of forming surface-bonded $\mathrm{OH}$ is through water oxidation via Reaction $7 .{ }^{16}$

Hydroxyl radicals may adsorb at the top, hollow, and bridge positions on all three surfaces, with the top position preferred for the (111) and (110) and the bridge position preferred on the (100) surface. $\mathrm{OH}$ on the (100) surface has the highest adsorption energy for low-index Pt planes, which may explain why this particular surface shows the lowest activity for the ORR in alkaline and perchloric acid media.
Hydrogen peroxide is unstable on the low index Pt surfaces and decays into hydroxyl radicals or a water molecule and an atomic oxygen.

The effect of a uniform external electric field on the adsorbate properties on the $\mathrm{Pt}_{9}(111)$ cluster has been studied by means of an $a b$ initio, DFT-based, cluster model approach. For all adsorbed species the applied electric field is predicted to have a strong impact and to cause considerable changes in the bond lengths, chargetransfer characteristics, and vibrational frequencies.

The current study demonstrates that DFT methods are capable of effectively describing adsorption geometries, charge transfers, and vibrational frequencies of the oxygen-containing species upon adsorption on low index Pt surfaces. We believe that the present paper provides new insights into the complicated problem of oxygen reduction in particular in low-temperature fuel cell applications. Further work in a similar direction should take into account the stabilization or destabilization of surface-adsorbed species by coadsorbed water molecules at different coverages.

\section{Acknowledgments}

The research program at Eindhoven was supported by grants from The Netherlands Organization of Scientific Research (NWO) and the Energy Research Centre of The Netherlands (ECN).

\section{References}

1. U. A. Paulus, A. Wokaun, G. G. Scherer, T. J. Schmidt, V. Stamenkovich, V. Radmilovich, N. M. Markovic, and P. N. Ross, J. Phys. Chem. B, 106, 41081 (2002).

2. A. Damjanovic, M. A. Genshaw, and J. O'M. Bockris, J. Phys. Chem., 45, 4057 (1964).

3. N. M. Markovic, T. J. Schmidt, V. Stamenkovic, and P. N. Ross, Fuel Cells, 1, 105 (2001).

4. E. F. Elstner, in Sauerstoffabhängige Erkrankungen und Therapien, Bl-Wiss.-Verl., Mannheim (1993).

5. N. M. Markovic and P. N. Ross, in Interfacial Electrochemistry, A. Wieckowski, Editor, p. 821, Marcel Dekker, New York (1999).

6. R. A. Sidik and A. B. Anderson, J. Electroanal. Chem., 528, 69 (2002).

7. A. C. Luntz, J. Grimblot, and D. E. Fowler, Phys. Rev. B, 39, 12903 (1989).

8. R. Adzic, in Electrocatalysis, J. Lipkowski and P. N. Ross, Editors, Chap. 5, p. 197, Wiley-VCH, New York (1998).

9. B. N. Grgur, N. M. Markovic, and P. N. Ross, Jr., Langmuir, 13, 6370 (1997).

10. N. M. Markovic, H. A. Gasteiger, and P. N. Ross, Jr., J. Phys. Chem., 100, 6715 (1996).

11. A. B. Anderson and T. V. Albu, J. Electrochem. Soc., 147, 4229 (2000)

12. T. Jacob, R. P. Muller, and W. A. Goddard III, J. Phys. Chem. B, 107, 9465 (2003).

13. A. Eichler and J. Hafner, Phys. Rev. Lett., 79, 4481 (1997).

14. B. N. Grgur, N. M. Markovic, and P. N. Ross, Can. J. Chem., 75, 1465 (1997).

15. C. Hartnig and M. T. M. Koper, J. Electroanal. Chem., 532, 165 (2002).

16. N. M. Markovic, T. J. Schmidt, B. N. Grgur, H. A. Gasteiger, R. J. Behm, and P. N. Ross, J. Phys. Chem., 103, 8568 (1999).

17. A. Panchenko, H. Dilger, E. Roduner, J. Kerres, M. Hein, A. Ullrich, and T. Kaz, in Proceedings of the 2nd European PEFC Forum, D. Stolten, B. Emonts, and R. Peters, Editors, Vol. 1, p. 79, European Fuel Cell Forum (2003).

18. J. L. Whitten and H. Yang, Surf. Sci. Rep., 24, 55 (1996).

19. (a) M. T. M. Koper, R. A. van Santen, S. A. Wasileski, and M. J. Weaver, J. Chem. Phys., 113, 4392 (2000); (b) S. A. Wasileski, M. J. Weaver, and M. T. M. Koper, J. Electroanal. Chem., 500, 344 (2001).

20. M. Garcia-Hernandez, D. Curulla, A. Clotet, and F. Illas, J. Chem. Phys., 113, 364 (2000).

21. D. T. Sawyer, Oxygen Chemistry, Oxford University Press, London (1991).

22. A. Groß, A. Eichler, J. Hafner, M. J. Mehl, and D. A. Papaconstantopoulos, Surf Sci., 539, 542 (2003).

23. C. Puglia, A. Nilsson, B. Hernnäs, O. Karis, P. Bennich, and N. Martenson, Surf. Sci., 347, 303 (1996).

24. P. D. Nolan, B. R. Lutz, P. L. Tanaka, J. E. Davis, and C. B. Mullins, J. Chem. Phys., 111, 3696 (1999).

25. B. C. Stipe, M. A. Rezaei, and W. Ho, Phys. Rev. Lett., 78, 4410 (1997).

26. M. Bauer, C. Lei, K. Read, R. Tobey, J. Gland, M. M. Murnane, and H. C. Kapteyn, Phys. Rev. Lett., 87, 025501 (2001).

27. J. L. Gland, B. A. Sexton, and G. B. Fisher, Surf. Sci., 95, 587 (1980).

28. G. B. Fisher and B. A. Sexton, Phys. Rev. Lett., 44, 683 (1980).

29. K. Bedürftig, S. Völkening, Y. Wang, J. Wintterlin, K. Jacobi, and G. Ertl, J. Chem Phys., 111, 11147 (1999)

30. G. E. Mitchell and J. M. White, Chem. Phys. Lett., 135, 84 (1987)

31. A. Michaelides and P. Hu, J. Chem. Phys., 114, 513 (2001).

32. (a) M. T. M. Koper, T. E. Shubina, and R. A. van Santen, J. Phys. Chem. B, 106, 686 (2002); (b) T. E. Shubina and M. T. M. Koper, Electrochim. Acta, 47, 3621 (2002).

33. P. Vassilev, M. T. M. Koper, and R. A. van Santen, Chem. Phys. Lett., 359, 337 (2002). 
34. D. Kim, B. Lee, and D. Lee, Bull. Korean Chem. Soc., 20, 6 (1999).

35. S. Nakanishi, Y. Mukouyama, K. Karasumi, A. Imanishi, N. Furuya, and Y. Nakato, J. Phys. Chem. B, 104, $4181(2000)$

36. Y. Mukouyama, S. Nakanishi, T. Chiba, K. Murakoshi, and Y. Nakato, J. Phys. Chem. B, 105, 7246 (2001).

37. P. A. Thiel and T. E. Madey, Surf. Sci. Rep., 7, 211 (1987).

38. H. Ogasawara, B. Brena, D. Nordlund, M. Nyberg, A. Pelmenschikov, L. G. M. Pettersson, and A. Nilsson, Phys. Rev. Lett., 89, 276102 (2002).

39. S. Meng, L. F. Xu, E. G. Wang, and S. Gao, Phys. Rev. Lett., 89, 176104 (2002)

40. (a) G. Kresse and J. Hafner, Phys. Rev. B, 47, 558 (1993); (b) G. Kresse and J. Hafner, Phys. Rev. B, 49, 14251 (1994); (c) G. Kresse and J. Furthmüller, Comput. Mater. Sci., 6, 15 (1996).

41. (a) P. E. Blöchl, Phys. Rev. B, 50, 17953 (1994); (b) G. Kresse and J. Joubert, Phys. Rev. B, 59, 1758 (1999).

42. S. H. Vosko, L. Wilk, and M. Nusair, Can. J. Phys., 58, 1200 (1980)

43. P. J. Perdew, J. A. Chevary, S. H. Vosko, K. A. Jackson, M. R. Pederson, D. J. Singhm, and C. Fiolhais, Phys. Rev. B, 46, 6671 (1992).

44. M. T. M. Koper, in Modern Aspects of Electrochemistry, Vol. 36, C. G. Vayenas, B. E. Conway, and R. E. White, Editors, p. 51, Kluwer Academic/Plenum Press, Norwell, MA (2003).

45. P. J. Hay and W. R. Wadt, J. Chem. Phys., 82, 270 (1985).

46. Gaussian 98, Revision A.7, M. J. Frisch, G. W. Trucks, H. B. Schlegel, G. E. Scuseria, M. A. Robb, J. R. Cheeseman, V. G. Zakrzewski, J. A. Montgomery, Jr., R. E. Stratmann, J. C. Burant, S. Dapprich, J. M. Millam, A. D. Daniels, K. N. Kudin, M. C. Strain, O. Farkas, J. Tomasi, V. Barone, M. Cossi, R. Cammi, B. Mennucci, C. Pomelli, C. Adamo, S. Clifford, J. Ochterski, G. A. Petersson, P. Y. Ayala, Q. Cui, K. Morokuma, D. K. Malick, A. D. Rabuck, K. Raghavachari, J. B. Foresman, J. Cioslowski, J. V. Ortiz, A. G. Baboul, B. B. Stefanov, G. Liu, A. Liashenko, P. Piskorz, I. Komaromi, R. Gomperts, R. L. Martin, D. J. Fox, T. Keith, M. A. Al-Laham, C. Y. Peng, A. Nanayakkara, C. Gonzalez, M. Challacombe, P. M. W. Gill, B. Johnson, W. Chen, M. W. Wong, J. L. Andres, C. Gonzalez, M. HeadGordon, E. S. Replogle, and J. A. Pople, Gaussian, Inc., Pittsburgh PA (1998).

47. P. E. M. Siegbahn, M. R. A. Blomberg, M. Wirstam nee Pavlov, and R. H. Crabtree, J. Biol. Inorg. Chem., 6, 460 (2001).

48. J. R. B. Gomes and F. Illas, Int. J. Mol. Sci., 2, 201 (2001)

49. J. C. Slater, Quantum Theory of Molecules and Solids, Vol. 4. The Self-Consistent Field for Molecules and Solids, McGraw-Hill, New York (1947).

50. V. Fock, Z. Phys., 61, $126(1930)$.

51. A. D. Becke, Phys. Rev. A, 38, 3098 (1988).

52. C. Lee, W. Yang, and R. G. Parr, Phys. Rev. B, 37, 785 (1988).

53. B. Miehlich, A. Savin, H. Stoll, and H. Preuss, Chem. Phys. Lett., 157, 200 (1989).

54. K. Ataka, T. Yotsuyanagi, and M. Osawa, J. Phys. Chem. Solids, 100, 10664 (1996).
55. P. S. Bagus, C. J. Nelin, W. Müller, M. R. Philpott, and H. Seki, Phys. Rev. Lett., 58, 559 (1987)

56. X. Li and A. A. Gewirth, J. Am. Chem. Soc., 125, 7086 (2003).

57. H. Härle, A. Lehnert, U. Metka, H. R. Volpp, L. Willms, and J. Wolfrum, Appl. Phys. B: Lasers Opt., 68, 567 (1999).

58. M. J. Weaver, Surf. Sci., 437, 215 (1999).

59. P. Stampfuß and W. Wenzel, Chem. Phys. Lett., 370, 478 (2003).

60. M. T. M. Koper and R. A. van Santen, J. Electroanal. Chem., 472, 126 (1999)

61. T. Li and P. B. Balbuena, J. Phys. Chem. B, 105, 9943 (2001).

62. X. Lin, N. J. Ramer, A. M. Rappe, K. C. Hass, W. F. Schneider, and B. L. Trout, J. Phys. Chem. B, 105, 7739 (2001).

63. Chemisorption and Reactivity on Supported Clusters and Thin Films, R. Lambert and G. Pacchioni, Editors, NATO ASI Series, Series E: Applied Sciences-Vol. 331, Kluwer Academic Publishers Group, Dordrecht (1996).

64. S. A. Wasileski, M. T. M. Koper, and M. J. Weaver, J. Chem. Phys., 115, 8193 (2001).

65. S. A. Wasileski, M. T. M. Koper, and M. J. Weaver, J. Am. Chem. Soc., 124, 2796 (2002).

66. M. E. Jacox, Vibrational and Electric Energy Levels of Polyatomic Transient Molecules, AIP, Woodbury, NJ (1994).

67. G. Hübner and E. Roduner, J. Mater. Chem., 9, 409 (1999).

68. N. Kizhakevariam, I. Villegas, and M. J. Weaver, J. Phys. Chem., 99, 7677 (1995).

69. L. P. L. Carrette, K. A. Friedrich, M. Huber, and U. Stimming, Phys. Chem. Chem. Phys., 3, 320 (2001).

70. M. J. Weaver, Appl. Surf. Sci., 67, 147 (1993).

71. C. H. Hamann and W. Vielstich, in Elektrochemie, Wiley-VCH, Weinheim (1998).

72. A. Panchenko, H. Dilger, J. Kerres, M. Hein, A. Ullrich, T. Kaz, and E. Roduner, Phys. Chem. Chem. Phys., 6, 2891 (2004).

73. S. Völkening, K. Bedürftig, K. Jacobi, J. Wintterlin, and G. Ertl, J. Phys. Rev. Lett., 83, 2672 (1999).

74. K. Huber and G. Herzberg, Molecular Spectra and Molecular Structure: Constants of Diatomic Molecules, Vol. 4, Van Nostrand Reinhold, New York (1979).

75. H. Nakatsuji and H. Nakai, Chem. Phys. Lett., 197, 339 (1992).

76. P. H. Krupenie, J. Phys. Chem. Ref. Data, 1, 423 (1972).

77. M. E. Jacox, Vibrational and Electronic Energy Levels of Polyatomic Transient Molecules, AIP, Woodbury, NJ (1994).

78. T. Shimanouchi, Table of Molecular Vibrational Frequencies, Consolidated Vol. 1, NSRDS, NBS-39, Washington, DC (1972).

79. Y. Tarchouna, M. Bahri, N. Jaidane, Z. Ben Lakhdar, and J. P. Flament, J. Chem Phys., 118, 1189 (2003). 